Article

\title{
The Impacts of Landscape Changes on Annual Mean Land Surface Temperature in the Tropical Mountain City of Sri Lanka: A Case Study of Nuwara Eliya (1996-2017)
}

\author{
Manjula Ranagalage ${ }^{1,2, *(\mathbb{D})}$, Yuji Murayama ${ }^{1}\left(\mathbb{D}\right.$, DMSLB Dissanayake $^{2,3, *(\mathbb{D})}$ \\ and Matamyo Simwanda $4 \mathbb{D}$ \\ 1 Faculty of Life and Environmental Sciences, University of Tsukuba, 1-1-1, Tennodai, Tsukuba, \\ Ibaraki 305-8572, Japan; mura@geoenv.tsukuba.ac.jp \\ 2 Department of Environmental Management, Faculty of Social Sciences and Humanities, \\ Rajarata University of Sri Lanka, Mihintale 50300, Sri Lanka \\ 3 Graduate School of Life and Environmental Sciences, University of Tsukuba, 1-1-1, Tennodai, Tsukuba, \\ Ibaraki 305-8572, Japan \\ 4 Department of Plant and Environmental Sciences, School of Natural Resources, Copperbelt University, \\ P.O. Box 21692, Kitwe 10101, Zambia; matamyo@gmail.com \\ * Correspondence: manjularanagalage@ssh.rjt.ac.lk or manjularanagalage@gmail.com (M.R.); \\ dissanayakedmslb@gmail.com (D.D.)
}

Received: 23 August 2019; Accepted: 1 October 2019; Published: 6 October 2019

check for updates

\begin{abstract}
Although urbanization has contributed to improving living conditions, it has had negative impacts on the natural environment in urbanized areas. Urbanization has changed the urban landscape and resulted in increasing land surface temperature (LST). Thus, studies related to LST in various urban environments have become popular. However, there are few LST studies focusing on mountain landscapes (i.e., hill stations). Therefore, this study investigated the changes in the landscape and their impacts on LST intensity (LSTI) in the tropical mountain city of Nuwara Eliya, Sri Lanka. The study utilized annual median temperatures extracted from Landsat data collected from 1996 to 2017 based on the Google Earth Engine (GEE) interface. The fractions of built-up (BL), forested (FL) and agricultural (AL) land, were calculated using land use and cover maps based on urban-rural zone (URZ) analysis. The urban-rural margin was demarcated based on the fractions of BL $(<10 \%)$, and LSTI that were measured using the mean LST difference in the urban-rural zone. Besides, the mixture of land-use types was calculated using the AL/FL and BL/FL fraction ratios, and grid-based density analysis. The results revealed that the BL in all URZs rapidly developed, while AL decreased during the period 1996 to 2017. There was a minimal change in the forest area of the Nuwara Eliya owing to the government's forest preservation policies. The mean temperature of the study area increased by $2.1^{\circ} \mathrm{C}$ from 1996 to 2017. The magnitude of mean LST between urban-rural zones also increased from $1.0^{\circ} \mathrm{C}(1996)$ to $3.5^{\circ} \mathrm{C}$ (2017). The results also showed that mean LST was positively correlated with the increase and decrease of the BL/FL and AL/FL fraction ratios, respectively. The grid-based analysis showed an increasing, positive relationship between mean LST and density of BL. This indicated that BL density had been a crucial element in increasing LST in the study area. The results of this study will be a useful indicator to introduce improved landscape and urban planning in the future to minimize the negative impact of LST on urban sustainability.
\end{abstract}

Keywords: land use and cover; land surface temperature; built-up land; agricultural land; gradient analysis; Nuwara Eliya; Sri Lanka 


\section{Introduction}

In recent decades, population growth and economic development have directly affected landscapes' transformations in developing countries [1]. Rapid changes in the landscape have resulted in the conversion of natural vegetation and agricultural land into built-up (impervious) land, such as buildings, parking lots, roads, and other constructions [1-4]. This has caused several environmental problems at local, regional, and global scales [5], such as decreases in agricultural land [6]; habitat destruction [5,7,8]; air, soil, and water contamination [9-11]; increases in vector-borne diseases, such as malaria and dengue [12]; decreases in green space [13,14]; and increases in land surface temperature (LST) [15-17].

Increasing temperatures in urban environments are largely an outcome of rapid urbanization and anthropogenic activities [18]. Built-up areas have been formed using several materials, such as concrete, flooring, pebbles, stone, and gravel, which decrease evapotranspiration, increase the sensitivity of the city and notably affect its local climate $[16,19,20]$. However, studying temperature changes based on the air temperature is challenging, as there is a lack of meteorological stations, especially in developing countries [21]. Thus, satellite remote-sensing data provides vital information for observing the temperature patterns in urban areas [21]. Several studies have been conducted by using vast range of remote sensing data, such as Modis data [22-25], Synthetic Aperture Radar (SAR) data [26], Nightlights data [27,28], Landsat data [17,29,30], Land Scan data [31-33], and fossil fuel $\mathrm{CO}_{2}$ emission data $[33,34]$, to understand LST patterns. Many urban landscapes from small to large scales have been studied worldwide $[16,35,36]$, including coastal cities $[16,33,37,38]$, desert cities [20,39], and mountain cities $[13,14]$. Mountain cities are attractive for rich people, as they have a cold climate and comfortable living conditions, which have resulted in rapid urban development [14]. Thus, studies focusing on mountain landscapes are vital for understanding the changing pattern of LST to introduce mitigation measures for comfortable living conditions.

A large number of studies have used two or more satellite images from different time points to analyze an LST pattern due to the unavailability of cloud-free images. However, the difference in the acquisition times might influence any resulting LST pattern due to varying environmental factors (wind speed, the Sun's radiation, surface moisture, and humidity) [4,32]. The use of more satellite images captured in multiple time points can potentially provide more specific information to understand the changing pattern of LST [4]. Still, it is not easy to analyze extensive earth observation data sets, because of issues of spatial and temporal resolution [40,41]. Thus, big data analysis platforms can be used as an alternative for conducting accurate results [40]. The Google Earth Engine (GEE) provides the potential to process a large number of satellite images and researchers can easily access free public data archives for more than thirty years of historical data [40]. Hence, in this study, we used GEE to extract the annual median LST for three-time points such as 1996, 2006, and 2017 based on several images captured during the selected years. We hypothesized that the use of many images captured in multiple time points would provide a more precise pattern of LST in the study area.

The spatial distribution of the LST intensity (LSTI) provides essential environmental information for understanding a temperature pattern in detail. The literature provides two methods that can be used to study LSTI. The first one is the categorization of land use and cover as the local climate zone and then following the cross cover comparison method to calculate the LSTI [13,14,42-44]. The second method involves determining the difference in the mean LST between urban and rural zones based on the urban-rural gradient analysis [13,14,45]. In this study, we used the second method. Other studies utilizing the urban-rural gradient analysis have shown that the urban-rural demarcation is essential for determining the temperature differences $[13,14]$.

Mountain cities in Asia have been developing since the colonization period of the 19th and 20th centuries [46,47]. The cool climate and natural landscapes became the most prominent factors driving the development of mountain cities. During the colonial period, cool climates were preferred, as they allowed the colonials to maintain their "western lifestyle." Mountain cities were also selected to avoid wasting illnesses, episodic pestilence, sunstroke, and depression [46,48]. As a result, most 
mountain cities have been experiencing rapid urbanization since the end of World War II until now. Notwithstanding the vast literature on the impacts of urbanization on landscape changes and other associated consequences, like increasing LST, mountain cities remain one of the landscapes that have not been extensively studied.

Nuwara Eliya is a historical city that developed during the British colonial period, as reflected in the city's architecture [49]. The British people preferred a cold climate and Nuwara Eliya was referred to as "Little England" [49]. They used Nuwara Eliya as a meeting place for wealthy British families [50]. Currently, several recreational sites, such as Lake Gregory, golf links, racecourses, and a large number of clubs, remain in Nuwara Eliya [50]. After gaining independence in 1948, Nuwara Eliya became renowned worldwide as a tourist destination in Sri Lanka, and thousands of tourists from Sri Lanka and overseas visited this area to enjoy the cold climate and natural beauty [49]. This has resulted in several environmental problems associated with urbanization in Nuwara Eliya. One of the critical environmental impacts of urbanization that has likely affected the mountain city Nuwara Eliya is the Urban Heat Island (UHI) resulting from variations in LST [13,14]. Still, previous studies related to LST have been focused on the Colombo City [3,4,37] and Kandy [13,51] in Sri Lanka.

Thus, in this study, we hypothesized that the rapid changes in the urban landscape of Nuwara Eliya influenced the patterns of LST. The study examined the changes in the urban landscape and their impacts on the spatiotemporal changes of LST, in order to contribute to efforts aimed at introducing proper landscape and urban planning in Nuwara Eliya. The study has three objectives to: (1) monitor urban landscape changes and their impacts on the spatial and temporal variations of LST intensity from 1996-2017 based on the urban-rural gradient analysis; (2) identify relationships between mean LST and the agricultural land (AL)/forested land (FL) and built-up land (BL)/FL fraction ratios; and (3) study the relationship between mean LST and densities of BL, FL, and AL based on the grid-based analysis method. The results of this study could be useful for enhancing capacity and knowledge to minimize the possible negative impacts of rapid urbanization in the study area.

\section{Materials and Methods}

\subsection{Study Area: Nuwara Eliya, Sri Lanka}

Nuwara Eliya is located in the central province of Sri Lanka and resides at latitudes of $6^{\circ} 54^{\prime} 21.94^{\prime \prime}$ to $7^{\circ} 2^{\prime} 28.53^{\prime \prime} \mathrm{N}$ and longitudes of $80^{\circ} 50^{\prime} 5.89^{\prime \prime}$ to $80^{\circ} 41^{\prime} 57.23^{\prime \prime} \mathrm{E}$ (Figure 1). The study area includes the landscape within a $7.5 \mathrm{~km}^{2}$ radius of the center of Nuwara Eliya. Nuwara Eliya is surrounded by one of the tallest mountains ( $2524 \mathrm{~m}$ high) in the study area, known as Pidurutalagala. The average elevation of Nuwara Eliya is about $1800 \mathrm{~m}$. Monthly rainfall in Nuwara Eliya ranges from approximately 71.5 to $226.8 \mathrm{~mm}$, with an annual average of $1905 \mathrm{~mm}$. The lowest average monthly rainfall is recorded in January, February, and March, resulting in a relatively dry period. According to the Meteorology Department of Sri Lanka, the daily mean temperature is about $15.9{ }^{\circ} \mathrm{C}$, with average minimum and maximum temperatures of $11.6^{\circ} \mathrm{C}$ and $20.2^{\circ} \mathrm{C}$, respectively. Nuwara Eliya is the most popular site in Sri Lanka among local and foreign tourists due to the cold climate that persists throughout the year. In terms of the urban development pattern, Nuwara Eliya exhibits a single locus. 


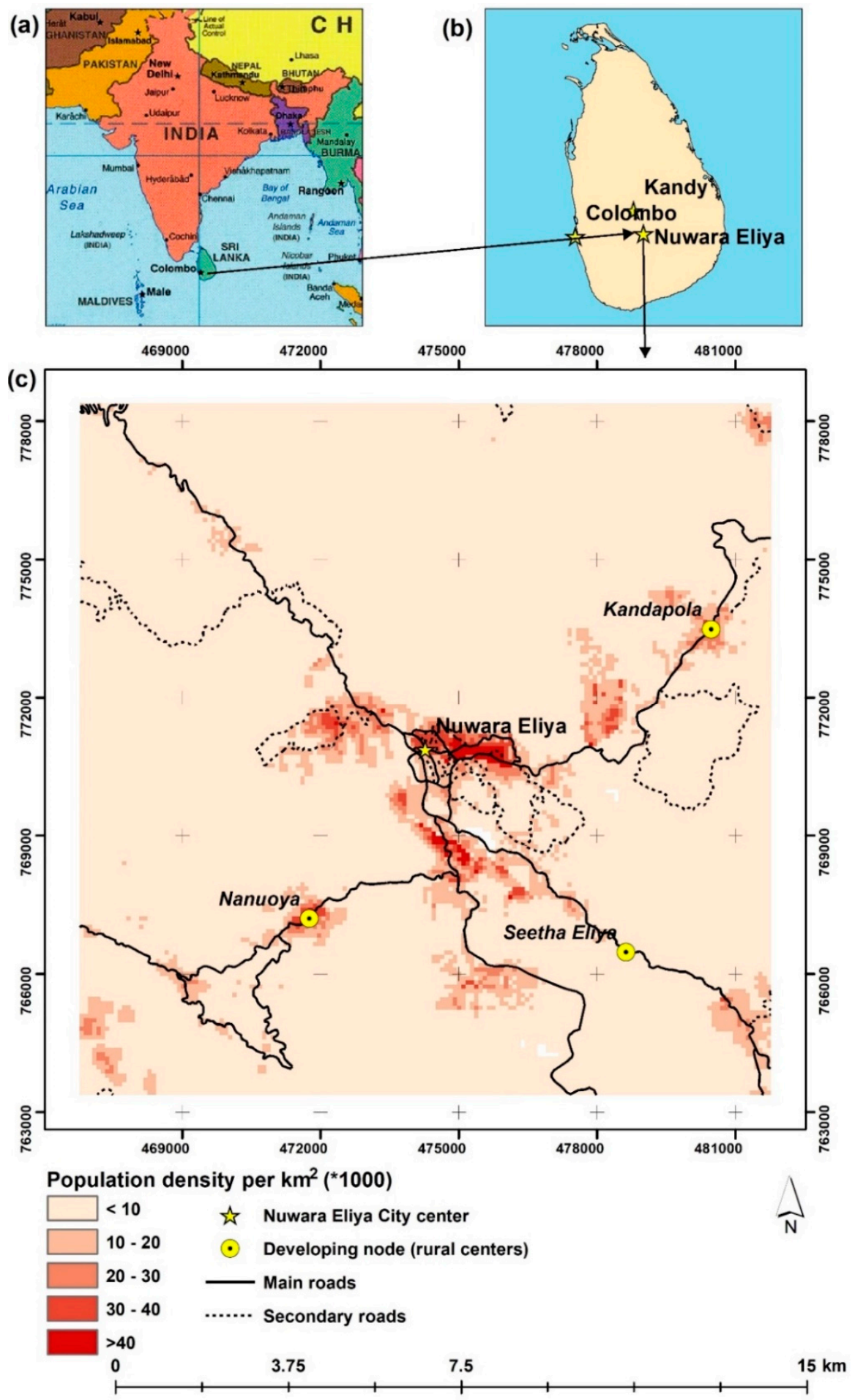

Figure 1. Study area: (a) map from part of South Asia (http://www.maps-world.net); (b) location of Nuwara Eliya; and (c) population density of Nuwara Eliya $(100 \times 100 \mathrm{~m})$.

\subsection{Overall Workflow}

Figure 2 shows the overall workflow of the study to achieve the objectives described above. The study workflow included five major steps: (i) extraction of median upper-atmosphere brightness temperature from the thermal bands of Landsat images (Figure 2a); (ii) retrieval of LST (Figure 2b); (iii) land use/land cover (LULC) classification into five classes, forest land (FL), built-up (BL), agriculture land (AL), other land, and water using machine learning algorithms, based on supervised classifications 
(Figure 2c); (iv) urban-rural gradient, statistical, and intensity analyses, based on the BL, FL, and AL fractions, $\mathrm{AL} / \mathrm{FL}$ and $\mathrm{BL} / \mathrm{FL}$ fraction ratios, and mean LST; and finally (v) grid analysis based on the mean LSTs and the densities of BL, FL, and AL.

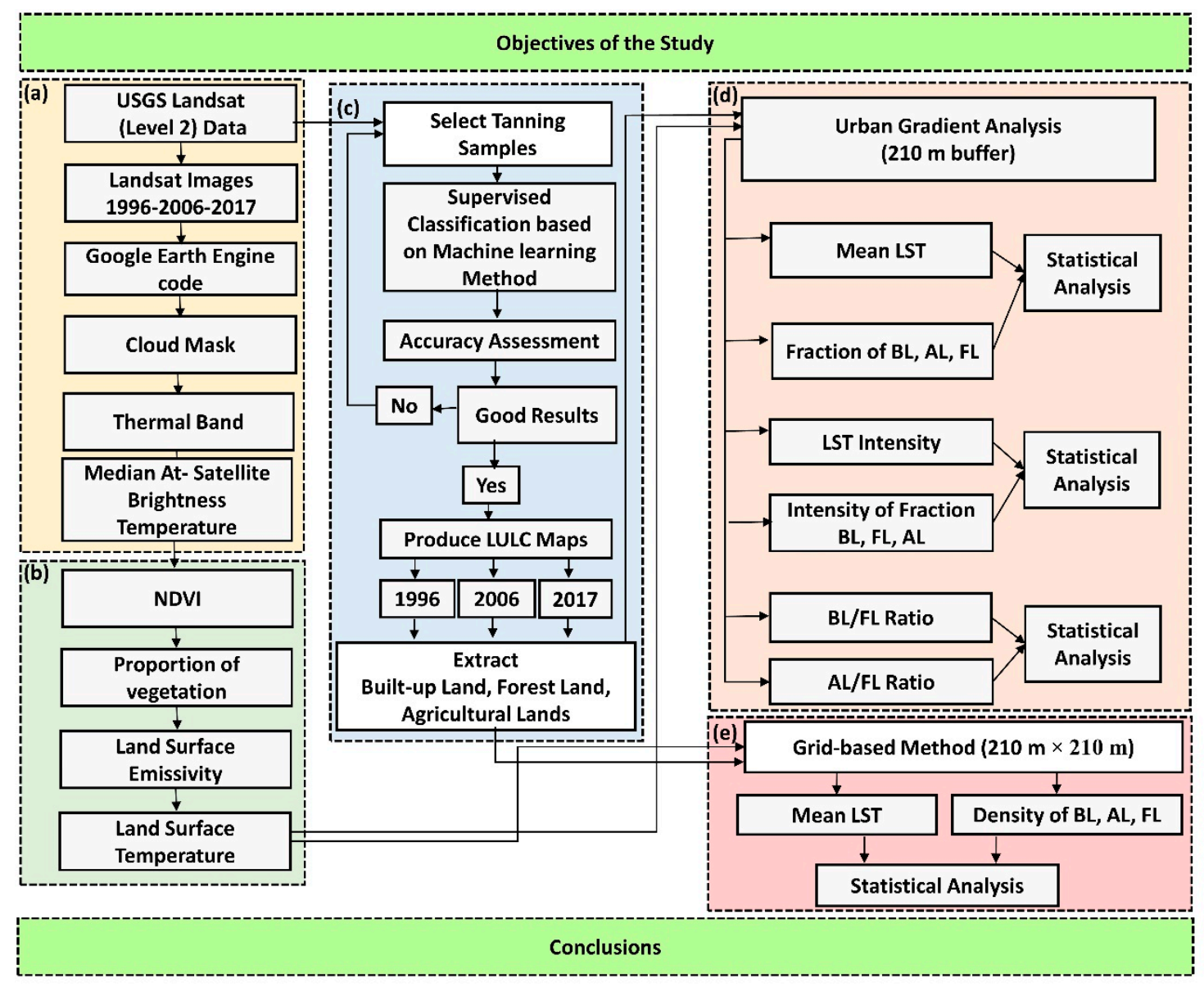

Figure 2. The workflow of the study. Note BL, FL, and AL refer to built-up land, forested land, and agricultural land, respectively.

\subsection{Calculating Annual Median At-Satellite Brightness Temperature Using the Google Earth Engine (GEE)}

The study employed the GEE to calculate annual median at-satellite brightness temperatures using atmospherically corrected pre-processed Landsat datasets (Level 2) [52]. We hypothesized that the use of more images would produce clearer output images to understand the LST patterns in the study area. Past studies have shown the aptness of this method to generate median LSTs in different areas $[40,41]$. In this process, several steps were performed as follows.

(i) The study area was defined and imported as an "Asset" in GEE, and subsequently used as the primary geometry source throughout the process. Masking was then conducted due to cloud disturbance in the available Landsat imageries. The cloud disturbance could be attributed to Nuwara Eliya being located in a tropical area.

(ii) The Image Collection tool in GEE was used to prepare the imagery for the study, including 15 images from 1996 (Landsat 5), 17 images from 2006 (Landsat 5), and 20 images from 2017 (Landsat 8) (Table A1).

(iii) Afterwards, median temperatures of each pixel were extracted for 1996, 2006, and 2017 by using "ee.reducer" methods available in GEE [53]. Extraction of the pixel based median temperatures was done to take care of inaccurate extraction caused by disturbance from clouds in the study area. Figure 3 shows the graphical illustration of creating image collection and the code used to generate the 
annual, median, at-satellite brightness temperature for each pixel of each year (provided in Annex Code A1 (Landsat 5TM) and A2 (Landsat 8)).

(iv) The extracted median temperatures based on the upper-atmosphere brightness temperatures from the thermal bands (in Kelvin) (band 6 for Landsat 5 and band 10 for Landsat 8) were used to calculate the LSTs, as described in Section 2.4.

(v) All extracted images were georectified using the WGS84/UTM 44N projection system before further processing.

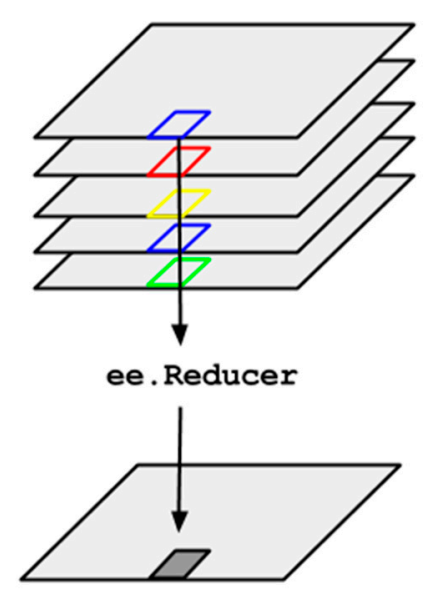

Figure 3. Graphical illustration of image collection [53].

\subsection{LST Calculations}

The extracted annual, median, at-satellite brightness temperatures, as mentioned in Section 2.3, were scaled using the land surface emissivity derived from Equation (1) [54].

$$
\varepsilon=\{\mathrm{mPV}+\mathrm{n}\}
$$

where $\mathrm{m}=(\varepsilon-\varepsilon)-(1-\varepsilon \sigma) ; \mathrm{F} \varepsilon \mathrm{V}$ and $\mathrm{n}=\varepsilon \mathrm{S}+(1-\varepsilon \mathrm{s}) \mathrm{F} \varepsilon \mathrm{v}$. $\varepsilon \mathrm{S}$ and $\varepsilon \mathrm{V}$ are the soil emissivity and vegetation emissivity, respectively. In this study, we used the result of [54] for $m=0.004$ and $n=0.986$. The proportion of vegetation $\left(\mathrm{P}_{\mathrm{v}}\right)$ was calculated using the normalized difference vegetation index (NDVI) based on Equation (2) [55].

$$
\mathrm{NDVI}=\frac{\rho_{\text {NIR }}-\rho_{\text {Red }}}{\rho_{\text {NIR }}+\rho_{\text {Red }}}
$$

where $\rho_{\text {NIR }}$ refers to the surface reflectance values of bands 4 (Landsat- 5 ) and 5 (Landsat- 8 ); and $\rho_{\text {Red }}$ refers to the surface reflectance values of bands 3 (Landsat-5), and 4 (Landsat-8 OLI).

$\mathrm{P}_{\mathrm{v}}$ was extracted using Equation (3).

$$
\mathrm{P}_{\mathrm{v}}=\left(\left(\mathrm{NDVI}-\mathrm{NDVI}_{\min }\right) /\left(\mathrm{NDVI}_{\max }-\mathrm{NDVI}_{\min }\right)\right)^{2}
$$

where, $\mathrm{P}_{\mathrm{v}}$ is the proportion of vegetation, NDVI is original NDVI value calculated using Equation (2), and $\mathrm{NDVI}_{\min }$ and $\mathrm{NDVI}_{\max }$ are the minimum and maximum values of the NDVI dataset, respectively.

The emissivity corrected images were used to extract LSTs using Equation (4) [3,30].

$$
\mathrm{LST}=\mathrm{T}_{\mathrm{b}} / 1+\left(\lambda \times \mathrm{T}_{\mathrm{b}} / \rho\right) \ln \varepsilon
$$

where $T_{b}$ is the at-satellite brightness temperature in degrees Kelvin; $\lambda$ is the central band wavelength of emitted radiance (11.5 $\mu \mathrm{m}$ for band 6 [30] and $10.8 \mu \mathrm{m}$ for band 10 [13]; $\rho$ is $\mathrm{h} \times \mathrm{c} / \sigma\left(1.438 \times 10^{-2} \mathrm{~m} \mathrm{~K}\right)$, with $\sigma$ as the Boltzmann constant $\left(1.38 \times 10^{-23} \mathrm{~J} / \mathrm{K}\right)$, h as Planck's constant $\left(6.626 \times 10^{-34} \mathrm{~J}\right.$ *s $)$, and $\mathrm{c}$ as 
the velocity of light $\left(2.998 \times 10^{8} \mathrm{~m} / \mathrm{s}\right)$; and $\varepsilon$ is the land-surface emissivity estimated using the NDVI method [54]. The calculated LST value (Kelvin) is then converted to ${ }^{\circ} \mathrm{C}$.

\subsection{Land Use/Land Cover (LULC) Mapping}

Machine learning methods, such as support vector machines (SVM), K-nearest neighbor, random forest, and neural networks, have been widely used to classify LULC [13,14]. Among these methods, the SVM has provided higher overall accuracy [56-59]. Thus, in this study, we used the SVM algorithm to conduct LULC mapping. The classification scheme used in the study included five LULC categories; namely, built-up land (BL), forested land (FL), agricultural land (AL), other lands, and water. The other lands category was comprised of a combination of grasslands and bare lands.

We produced three LULC maps containing the five LULC categories (BL, FL, AL, other land and water) for the years 1996, 2006, and 2017 with overall accuracies of $85 \%, 93 \%$, and $92 \%$, respectively (see Tables A2-A4). The accuracy was assessed by using 500 reference points generated by a stratified random sampling method [14] for all the LULC categories. Google Earth imageries were used to assess the accuracy of the classified LULC maps for 2006 and 2017. The accuracy assessment for the 1996 LULC map was conducted with the aid of available topographic maps and different band combinations of Landsat imageries.

\subsection{LST Intensity (LSTI) Measurement}

The LSTI was calculated based on the urban-rural gradient analysis approach, which involves the creation of concentric rings or buffer zones around the city center with standard distance intervals extending to the rural areas $[13,14,42]$. Urban-rural gradient analysis has been conducted to identify the spatial and temporal variations in environmental variables in many previous environmental studies [13,14,16,20,60,61]. In this study, thirty-five $210 \mathrm{~m}$ buffer zones (hereafter referred to as urban-rural zones (URZs)) were created for the study area. The mean LST of each URZ was then extracted using zonal statistics. The fractions of BL, FL, and AL were determined by calculating their respective proportions in each URZ. Of note is that previous studies combined AL and FL into one LULC category defined as green space $[13,14,16]$. However, AL has been one of the key drivers of LULC changes in the study area. Therefore, AL in Nuwara Eliya and its surroundings was considered separately.

The magnitude of the LSTI along the urban-rural gradient (LSTI ${ }_{U-R}$ ) was determined based on the $\Delta$ mean LST, $\Delta$ fraction of $\mathrm{BL}, \Delta$ fraction of FL, and $\Delta$ fraction of $\mathrm{AL}$, following methodology proposed by Estoque and Murayama [14]. To calculate LSTI $_{\mathrm{U}-\mathrm{R}}$, we first determined the $\Delta$ mean LST by finding the difference between the mean LST in the URZ with the highest fractions of BL, FL and $\mathrm{AL}$ (defined as $U R Z_{1}$ ) and other $\mathrm{URZ}_{\mathrm{s}}$ (i.e., $\mathrm{URZ}_{1}-\mathrm{URZ}_{2} \ldots 35$ ). We then applied the same method to determine the $\Delta$ fraction of $\mathrm{BL}, \Delta$ fraction of $\mathrm{FL}$, and $\Delta$ fraction of $\mathrm{AL}$ along the urban-rural gradient. We used the same threshold for delineating the urban and rural zones as the authors of [13,14]; i.e., from the city center, all URZs with an $>10 \%$ fraction of BL were considered as urban and those beyond the first URZ with $<10 \%$ fraction of BL were considered as rural.

\subsection{AL/FL and BL/FL Fraction Ratios and Their Intensities}

The AL/FL and BL/FL fraction ratios were calculated using the URZs created in Section 2.6. Ranagalage et al., 2018 [13] proposed the green space (GS)/impervious surface (IS) fraction ratio and its intensity, and we followed their methodology to extract $\mathrm{AL} / \mathrm{FL}$ and $\mathrm{BL} / \mathrm{FL}$ in each URZ using Equations (5) and (6), respectively.

$$
\begin{aligned}
& \mathrm{AL} / \mathrm{FL} \text { fraction ratio }=\frac{\mathrm{ALz}}{\mathrm{FLz}} \\
& \mathrm{BL} / \mathrm{FL} \text { fraction ratio }=\frac{\mathrm{BLz}}{\mathrm{FLz}}
\end{aligned}
$$




\subsection{Grid-Based Analysis}

The grid-based method was used to analyze the spatial distributions of the densities of BL, FL, $\mathrm{AL}$, and mean LSTs in 1996, 2006, and 2017. In this analysis, we used $210 \mathrm{~m} \times 210 \mathrm{~m}$ grids $(7 \times 7$ pixels $)$ to demarcate the relationships between BL, FL, and AL density with mean LST. The $210 \times 210 \mathrm{~m}$ grid size was used in previous studies and showed a high correlation with mean LST [16,39,44,62]. After the creation of the set of grids, the mean LST and the densities of BL, FL, and AL in each grid were calculated. Then, scatter plots were created and linear regression analysis was performed to identify the relationships between mean LST and densities of BL, FL, and AL.

\section{Results}

\subsection{Landscape Changes and LST Distribution of Nuwara Eliya}

The results revealed that Nuwara Eliya experienced rapid urbanization in the last 21 years. The built-up area increased from 289.9 ha to 2,080.4 ha from 1996 to 2017 with an annual growth rate of 85.3 ha per year (Figure 4 and Tables 1 and 2). The forest area did not change significantly due to the implementation of forest reserves by the government [63]. It was observed that the rapid changes in the built-up land negatively affected the agricultural sector. The area of agricultural land decreased from 8503.2 ha to 6583.9 ha from 1996 to 2017 (Table 1).

Table 1. Details of the land use/land cover (LULC) changes in Nuwara Eliya (1996, 2006, and 2017).

\begin{tabular}{ccccccc}
\hline \multirow{2}{*}{ Land Use/Cover } & $\mathbf{1 9 9 6}$ & \multicolumn{2}{c}{$\mathbf{2 0 0 6}$} & $\mathbf{2 0 1 7}$ \\
\cline { 2 - 7 } & Area (ha) & $\mathbf{\%}$ & Area (ha) & $\mathbf{\%}$ & Area (ha) & \% \\
\hline Built-up & 289.9 & 1.3 & 785.5 & 3.5 & 2080.4 & 9.3 \\
Forest & $13,076.7$ & 58.2 & $13,502.1$ & 60.1 & $13,234.3$ & 58.9 \\
Agricultural Land & 8503.2 & 37.9 & 8085.5 & 36 & 6583.9 & 29.3 \\
Other Land & 511.8 & 2.3 & 6 & 0 & 481.8 & 2.1 \\
Water & 73.4 & 0.3 & 75.9 & 0.3 & 74.6 & 0.3 \\
\hline Total & 22,455 & 100 & 22,455 & 100 & 22,455 & 100 \\
\hline
\end{tabular}

Table 2. LULC changes during 1996-2006, 2006-2017, and 1996-2017.

\begin{tabular}{|c|c|c|c|c|c|c|}
\hline \multirow[b]{2}{*}{ Land Use/Cover } & \multicolumn{2}{|c|}{ 1996-2006 } & \multicolumn{2}{|c|}{ 2006-2017 } & \multicolumn{2}{|c|}{ 1996-2017 } \\
\hline & $\begin{array}{c}\text { Land } \\
\text { Use/Cover } \\
\text { Changes (ha) }\end{array}$ & $\begin{array}{c}\text { Annual } \\
\text { Growth Rate } \\
\text { (ha per year) }\end{array}$ & $\begin{array}{c}\text { Land } \\
\text { Use/Cover } \\
\text { Changes (ha) }\end{array}$ & $\begin{array}{l}\text { Annual } \\
\text { Growth Rate } \\
\text { (ha per year) }\end{array}$ & $\begin{array}{c}\text { Land } \\
\text { Use/Cover } \\
\text { Changes (ha) }\end{array}$ & $\begin{array}{c}\text { Annual } \\
\text { Growth Rate } \\
\text { (ha per year) }\end{array}$ \\
\hline Built-up & 495.6 & 49.6 & 1294.9 & 117.7 & 1790.6 & 85.3 \\
\hline Forest & 425.3 & 42.5 & -267.8 & -24.3 & 157.6 & 7.5 \\
\hline Agricultural Land & -417.7 & -41.8 & -1501.7 & -136.5 & -1919.3 & -91.4 \\
\hline
\end{tabular}

Figure 4d-f shows the spatial distribution of LST in Nuwara Eliya for the years 1996, 2006, and 2017, respectively. In 1996, LST ranged between 9.1 and $29.2^{\circ} \mathrm{C}$ with a mean value of $18.9^{\circ} \mathrm{C}$. In 2006 , LST ranged between 5.9 and $30.2^{\circ} \mathrm{C}$ with a mean value of $17.9^{\circ} \mathrm{C}$. In 2017 , LST ranged between 14.3 and $31.0^{\circ} \mathrm{C}$ with a mean value of $21.0^{\circ} \mathrm{C}$. Therefore, the mean LST exhibited an increasing trend from 1996 to 2017 . The mean LST increased by $2.1^{\circ} \mathrm{C}$ during the past 21 years. Figure $4 \mathrm{~d}-\mathrm{f}$ shows increasing temperatures in the city center and in the southwestern and northeastern areas. The observed pattern of increasing temperatures was similar to the increase in BL. 
(a)

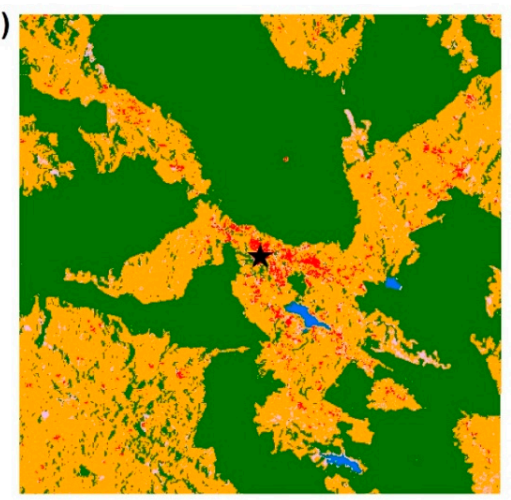

(b)

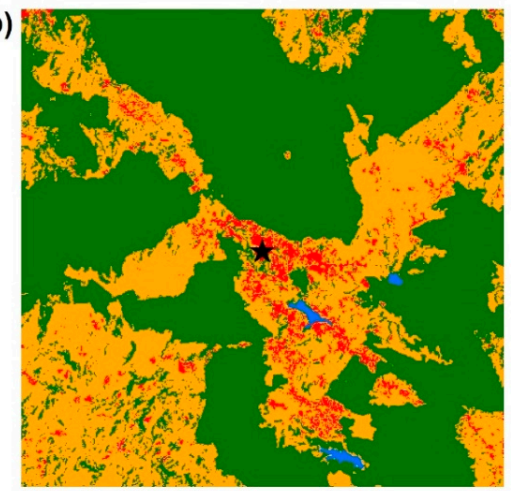

(c)

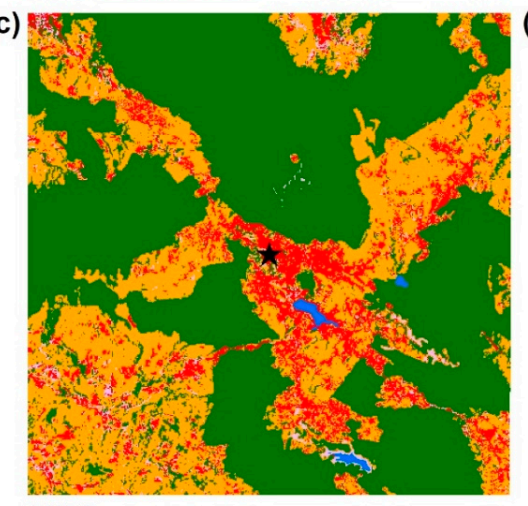

LULC

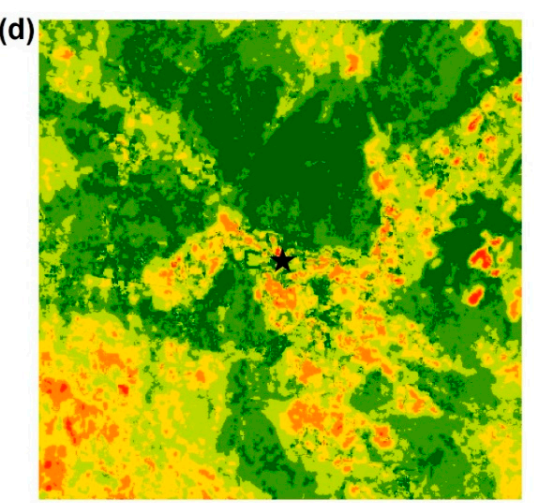

(e)

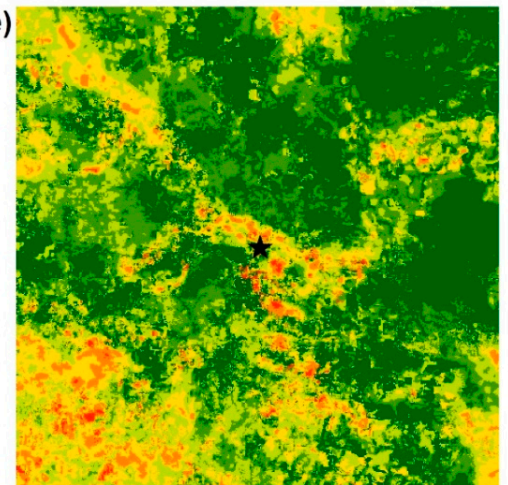

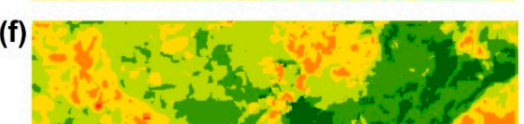

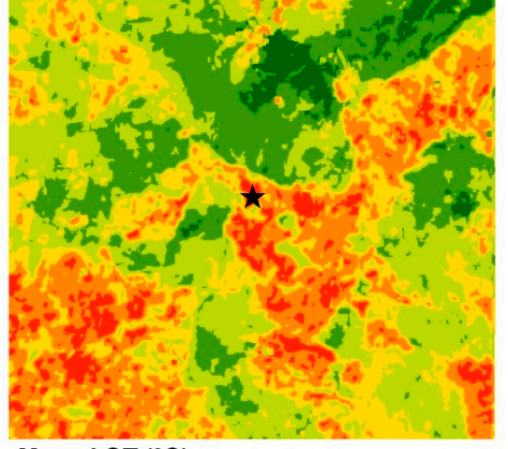

\section{Mean LST $\left({ }^{\circ} \mathrm{C}\right)$}

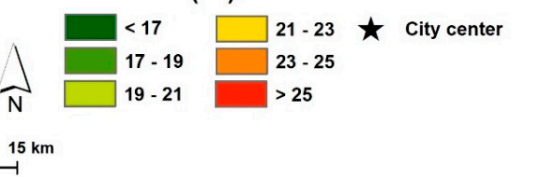

Figure 4. Land use/cover maps and land surface temperature (LST) values in Nuwara Eliya: land use/cover in (a) 1996, (b) 2006, and (c) 2017; and LST in (d) 1996, (e) 2006, and (f) 2017.

\subsection{Magnitude and Trend of LSTI}

\subsubsection{LSTI $_{\mathrm{U}-\mathrm{R}}$ along the Urban-Rural Gradient}

Figure $5 \mathrm{a}-\mathrm{c}$ shows the spatial pattern of mean LSTs and the fractions of BL, FL, and AL along the urban-rural gradient. The highest mean LST value was recorded in the URZ $\mathrm{U}_{1}$ near the city center. In 1996, the mean LST of $\mathrm{URZ}_{1}$ was $19.8^{\circ} \mathrm{C}$ which decreased to $18.9^{\circ} \mathrm{C}$ in 2006 and increased to $24.4^{\circ} \mathrm{C}$ in 2017. Conversely, the mean LST of all other URZs increased from 1996 to 2017. The results revealed that the mean LST of all other URZs ranged from $18.9^{\circ} \mathrm{C}$ to $21.2^{\circ} \mathrm{C}$ between 1996 and 2017. The results further revealed that the lowest temperatures were recorded in $\mathrm{URZ}_{12}$ in 1996, URZ 10 in 2006, and $\mathrm{URZ}_{19}$ in 2017 (Figure 5). 
The fraction of BL increased rapidly between 1996 and 2017. In $\mathrm{URZ}_{1}$, the fraction of BL increased by $32.4 \%, 48.7 \%$, and $58.7 \%$, in 1996, 2006, and 2017, respectively. The fraction of FL did not significantly change during the last 21 years. However, rapid changes in AL occurred in all URZs throughout the study's temporal extent. The lowest fraction of AL was continually recorded in $\mathrm{URZ}_{1}$ and exhibited a decreasing pattern. The AL fraction in URZ $\mathrm{U}_{1}$ was $43.6 \%$ in $1996,29.6 \%$ in 2006, and $15.8 \%$ in 2017.

Figure $5 \mathrm{~b}$ shows the results of the statistical analysis of mean LST with the fractions of BL, FL, and AL. The mean LST had a strongly significant, positive correlation $(p<0.001)$ with the fraction of BL at all the three time-points. The fraction of FL exhibited a strongly significant, negative correlation $(p<0.001)$ with mean LST. On the other hand, mean LSTs exhibited dissimilar relationships with the fractions of AL in 1996, 2006, and 2017. In 1996, the mean LST had a significant, positive correlation $(p<0.001)$ with the fraction of AL. In 2006, the mean LST and the fraction of AL had a weak relationship $(p<0.5)$, and in 2017, the mean LST had a significant, negative correlation with the fraction of AL $(p<0.1)$.

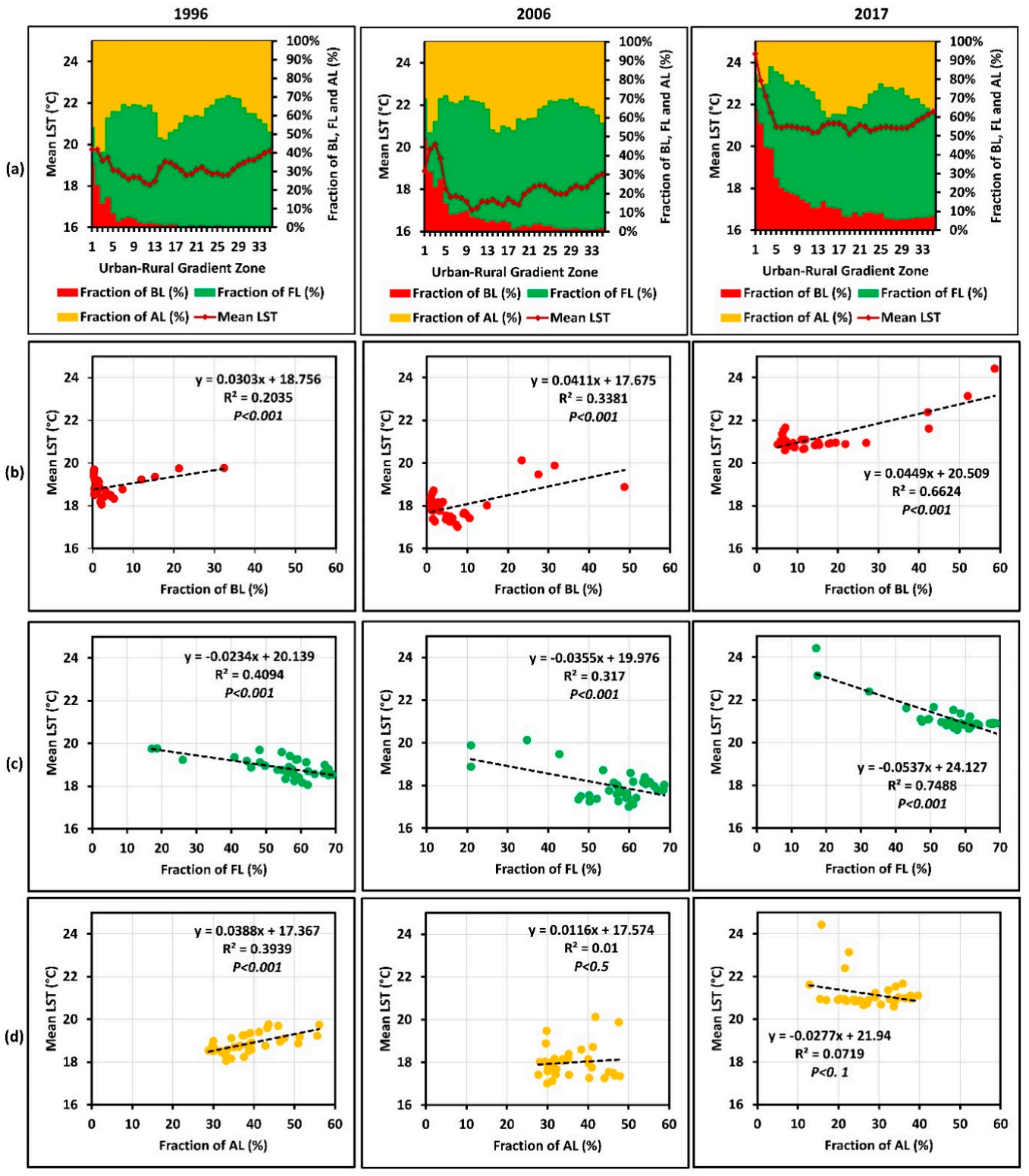

Figure 5. (a) Spatial distribution of mean LST, and the fractions of BL, FL, and AL along the urban-rural gradient; and scatter plots of the mean LST and fractions of (b) BL, (c) FL, and (d) AL. Note: changes in $\mathrm{BL}, \mathrm{FL}$, and AL types of land are not independent of each other. 


\subsubsection{The Magnitude of $\mathrm{LSTI}_{\mathrm{U}-\mathrm{R}}$ along the Urban-Rural Gradient}

The magnitudes of the mean LST and fractions of BL, FL, and AL were calculated based on URZ as described in Section 2.6 above. The $\Delta$ mean LST in URZ 13 showed a considerable decrease in 1996 and 2006. However, the decrease shifted to $\mathrm{URZ}_{20}$ in 2017 (Figure 6a). The $\Delta$ fractions of BL, FL, and AL also showed a similar pattern. The $\Delta$ mean LST had a significant relationship (positive) with the $\Delta$ fraction of BL, and a strong relationship (negative) with the $\Delta$ fraction of FL. The $\Delta$ mean LST exhibited a significant, positive relationship in $1996(p<0.001)$, and in $2006(p<0.5)$, with the $\Delta$ fraction of AL. However, the relationship changed in 2017, showing a weak, negative correlation $(p<0.5)$ with the $\Delta$ fraction of AL.

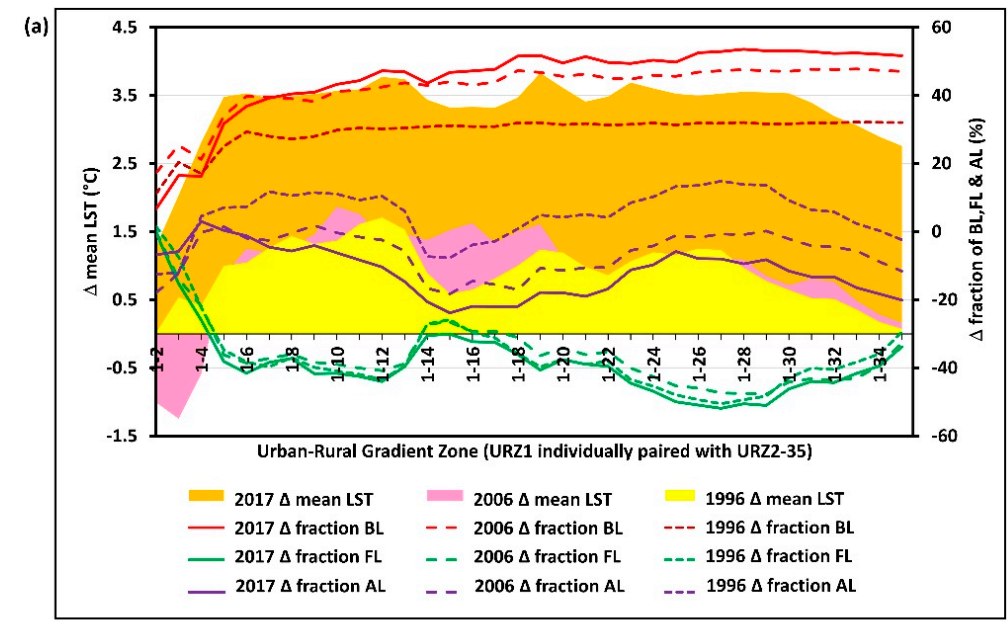

(b)
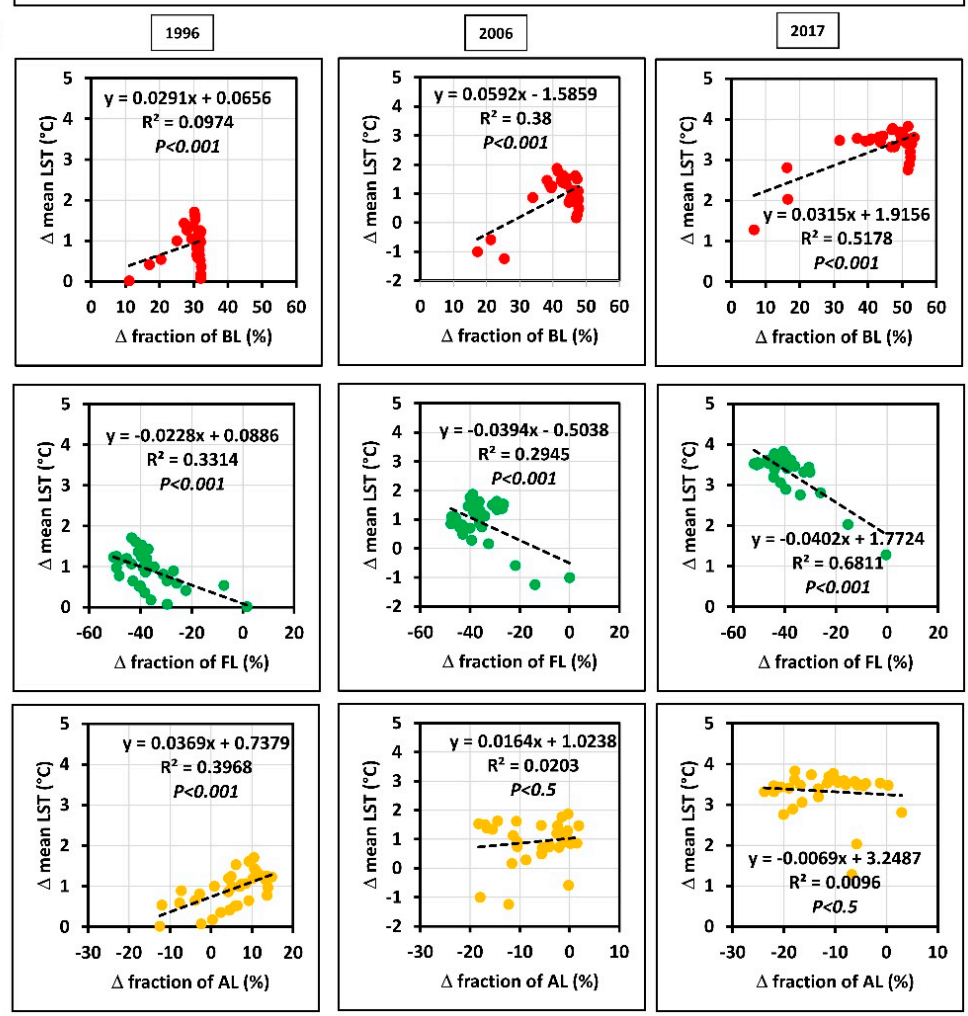

Figure 6. (a) Magnitudes of the trends of LST intensity $(\mathrm{LSTI})_{\mathrm{U}-\mathrm{R}}\left({ }^{\circ} \mathrm{C}\right)$, and fractions of $\mathrm{BL}$, FL, and AL along the URZ; and (b) statistical relationships between the magnitudes of mean LSTs and fractions of BL, FL, and AL in Nuwara Eliya during 1996, 2006, and 2017. Note: changes in BL, FL, and AL types of land are not independent of each other. 


\subsection{AL/FL and BL/FL Ratios}

An annual decrease in AL of 91.6 ha was observed from 1996 to 2017 (Table 2). FL was stable due to the protection measures implemented by the Forest Department of Sri Lanka (Table 1). A rapid decreasing trend in the AL/FL fraction ratio was observed from 1996 to 2017. The AL/FL fraction ratio decreased in all zones from $\mathrm{URZ}_{1}$ to $\mathrm{URZ}_{35}$ with average values of $0.84,0.7$, and 0.53 in 1996, 2006, and 2017 , respectively (Figure 7a). The mean LST values had a significant $(p<0.001)$, positive relationship with the AL/FL fraction ratio. Figure 7c shows the statistical relationship between the change in mean LST and $\Delta(\mathrm{AL} / \mathrm{FL})$ fraction ratio along the urban-rural gradient, and the result shows a significant positive relationship in all the three time-points in this study.

(a)

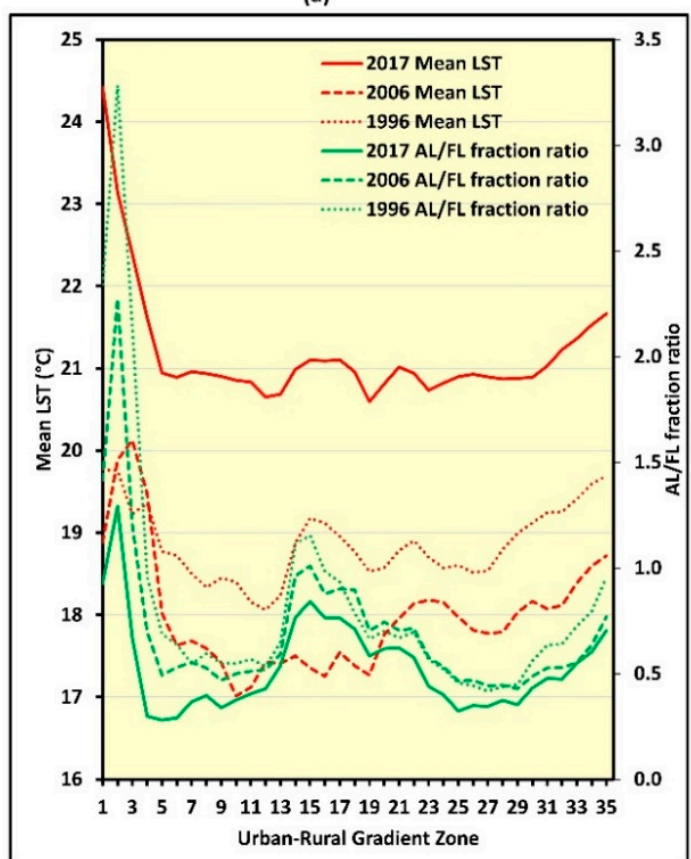

(b)

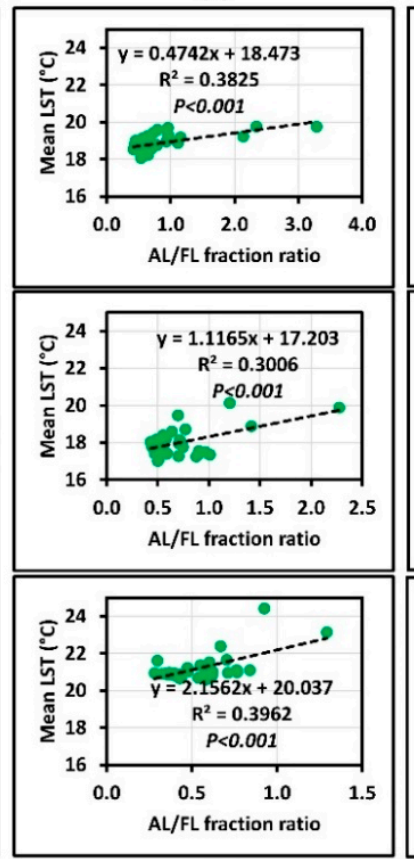

(C)

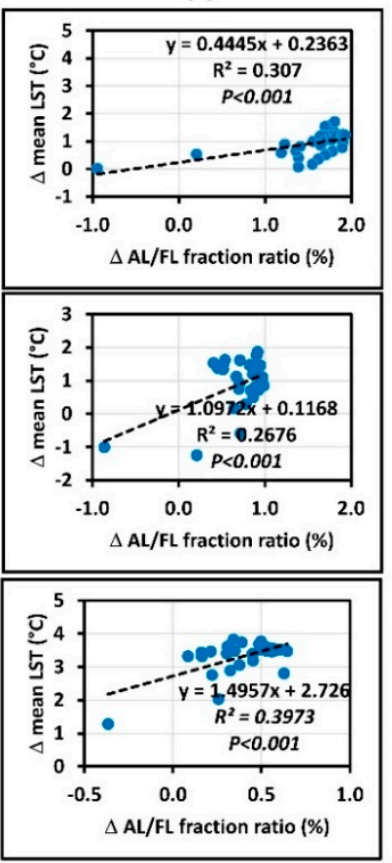

Figure 7. (a) Spatial distribution of the mean LST, AL/FL fraction ratio; (b) scatter plots of the mean LST and AL/FL fraction ratio; and (c) the $\Delta$ (mean LST) $\left({ }^{\circ} \mathrm{C}\right)$ and $\Delta(\mathrm{AL} / \mathrm{FL})$ fraction ratio in Nuwara Eliya in 1996, 2006, and 2017.

The BL/FL ratio increased from 1996 to 2017, with average values of $0.13,0.22$, and 0.42 in 1996, 2006, and 2017, respectively (Figure 8a). The mean LST exhibited a significant $(p<0.001)$, positive relationship with the BL/FL fraction ratio (Figure $8 b$ ). The relationship between the change in mean $\mathrm{LST}$ and $\Delta(\mathrm{BL} / \mathrm{FL})$ fraction ratio is presented in Figure $8 \mathrm{c}$. The results revealed that there was a strongly significant, positive relationship between the change in mean LST and $\Delta(\mathrm{BL} / \mathrm{FL})$ fraction ratio for all the three time-points.

\subsection{The Density of BL, FL, and AL Compared to Mean LST}

Figure 9a shows the spatial distribution of mean LST and the density of BL, FL, and AL in 1996, 2006, and 2017. High temperatures were observed around the city center and the northwestern and southwestern parts of the study area. The BL density was also high around the city center area in 1996 and it spread in the southern, southwestern and southeastern directions within the Nuwara Eliya area in 2006 and 2017. The FL density had an opposite pattern, showing low FL densities around all areas of high BL densities in all the three-time points. However, AL density showed a decreasing trend, especially in the city center area and southwestern direction of the study area. 
Figure $9 \mathrm{~b}$ shows the relationship between the densities of BL, FL, AL, and mean LST based on the grid-based analysis. The mean LST was statistically significant with the densities of BL, FL, and AL in all the three-time points $(p<0.001)$. There was an increasing trend of a positive correlation between BL density and mean LST from 1996 to 2017. The correlation between mean LST and the density of FL showed a significant negative relationship throughout the study period. In addition to that, there was a decreasing trend of a positive correlation between AL density and mean LST from 1996 to 2017.

(a)

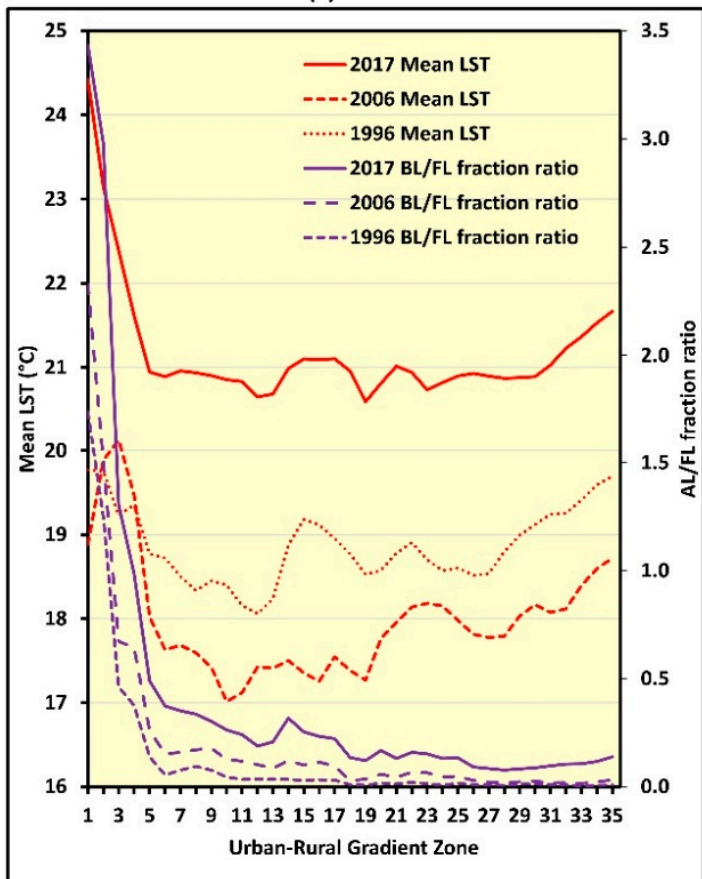

(b)

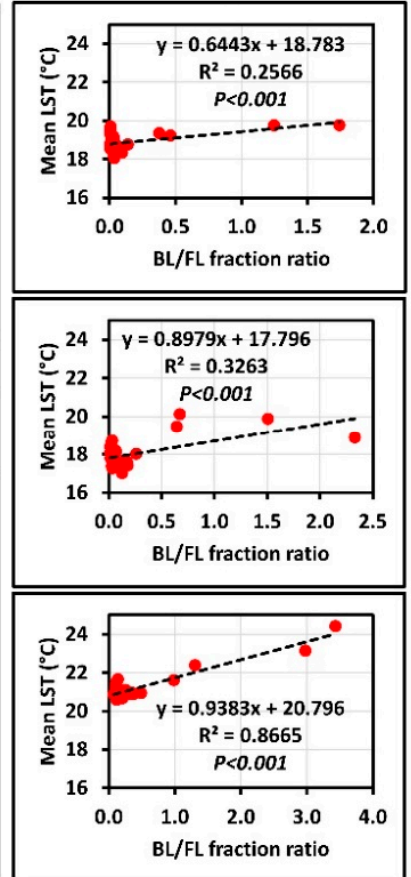

(C)

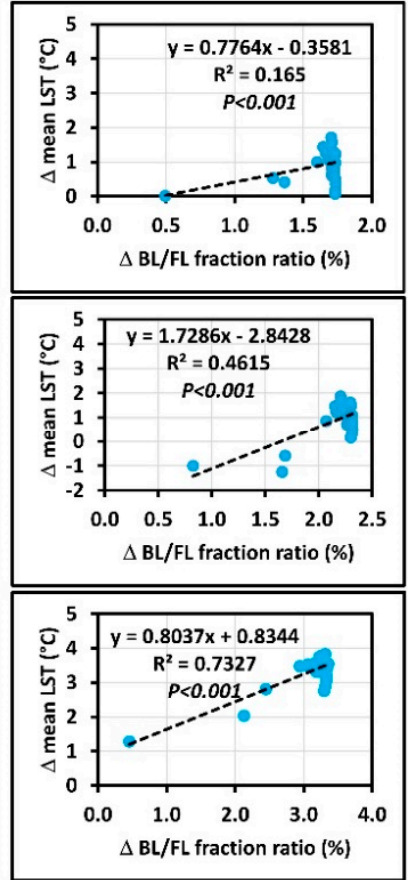

Figure 8. (a) Spatial distribution of the mean LST and BL/FL fraction ratio; (b) scatter plots of the mean LST and BL/FL fraction ratio; and (c) $\Delta$ (mean LST) $\left({ }^{\circ} \mathrm{C}\right)$ and $\Delta(\mathrm{BL} / \mathrm{FL})$ fraction ratio in Nuwara Eliya in 1996, 2006, and 2017. 
1996

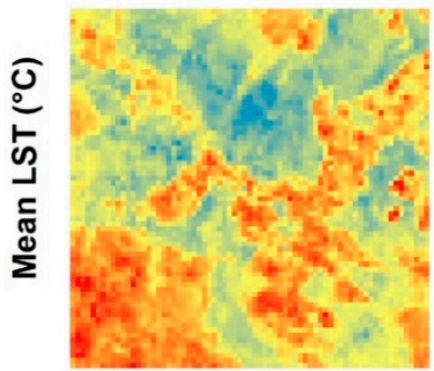

Low: $\mathbf{1 2 . 9}$ High: $\mathbf{2 6 . 0}$

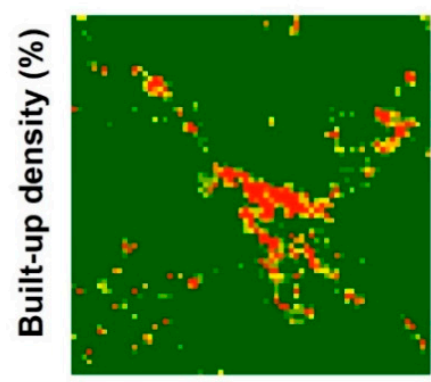

Low: 0
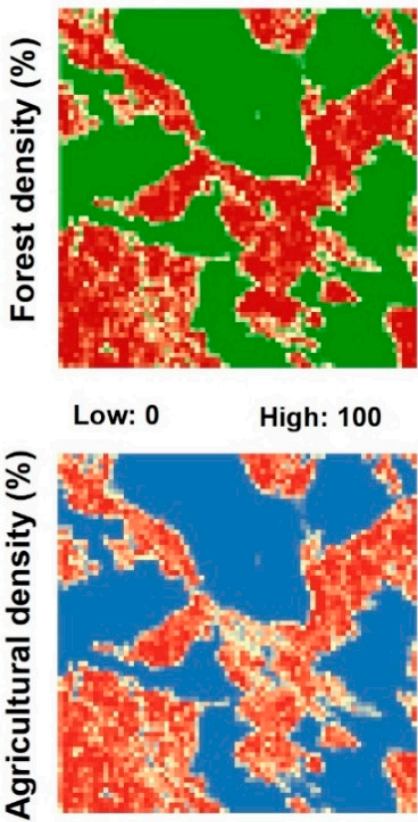

Low: 0

High: 100

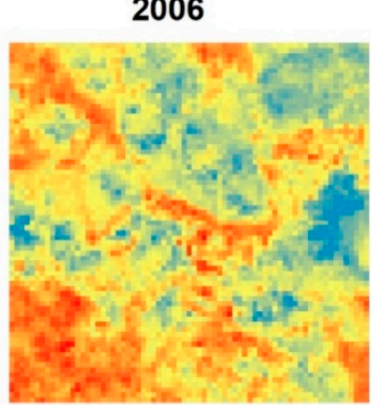

Low: $9.3 \quad$ High:26.0

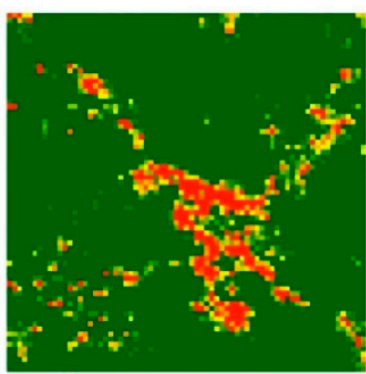

Low: 0
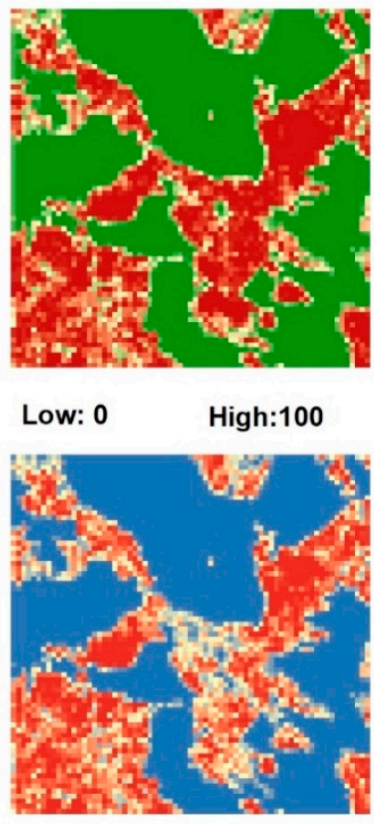

Low: 0
High:100
2017

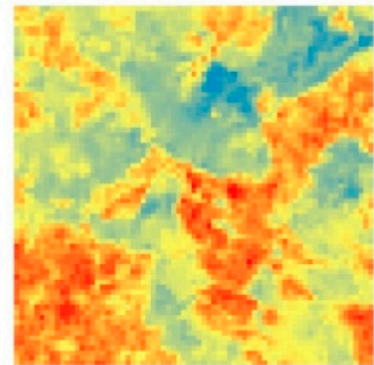

High

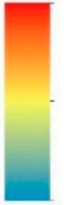

Low

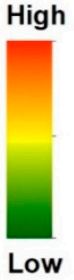

Low: 0

High: 100
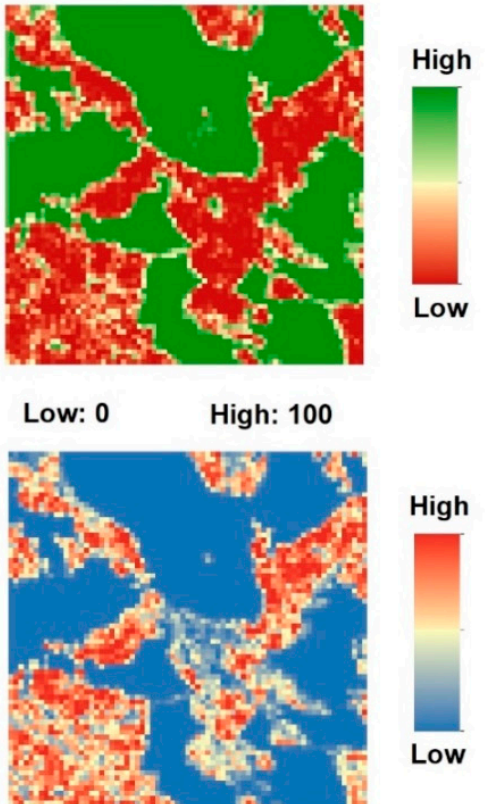

Low: 0

High:100

(a)

Figure 9. Cont. 

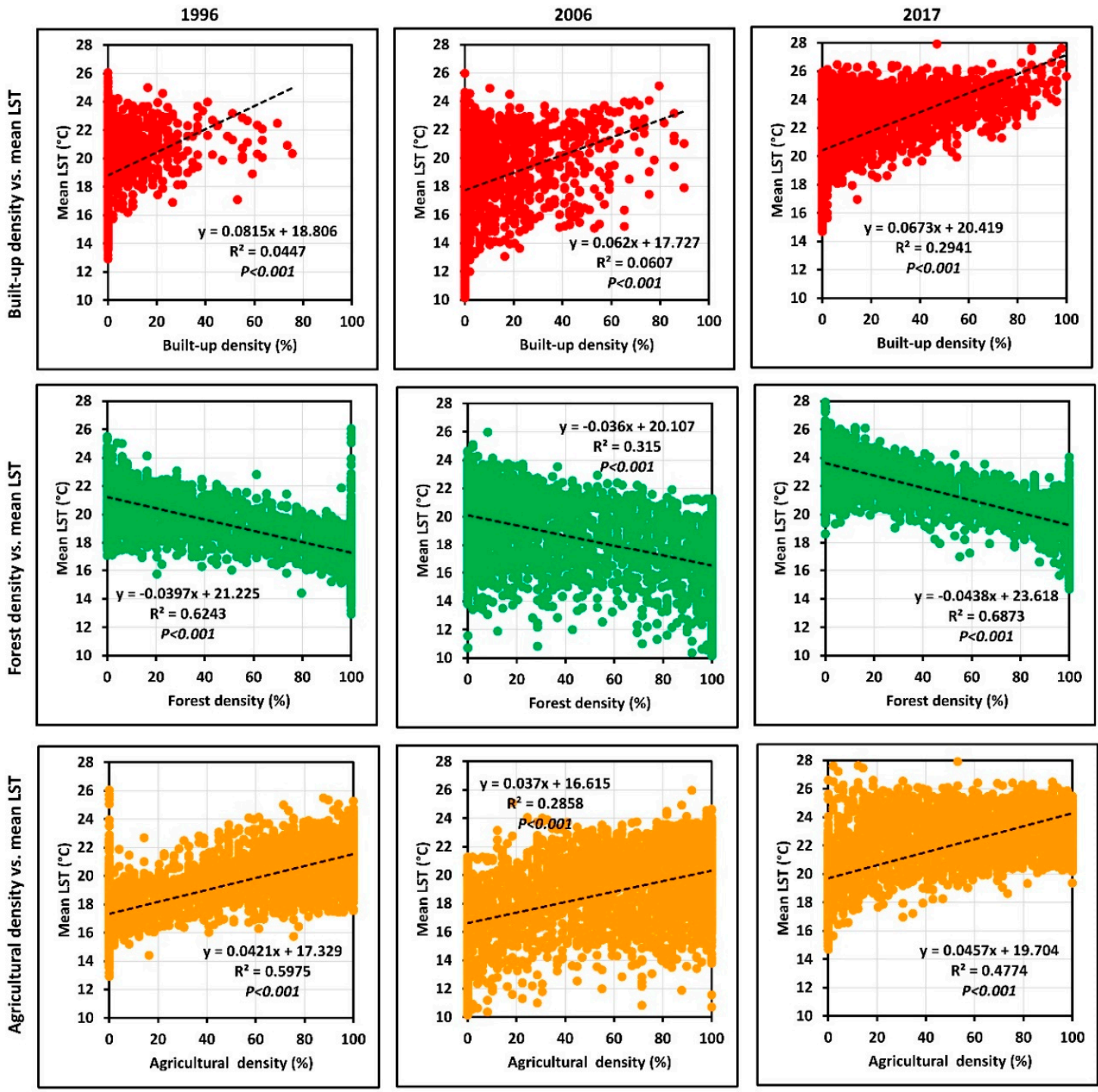

(b)

Figure 9. (a) Graphical view of the $210 \times 210 \mathrm{~m}$ polygon grid showing maps of mean LST, built-up density, forest density, and agricultural density in 1996, 2006, and 2017; (b) Scatterplots showing the relationship between the densities of BL, FL, AL, and mean LST in 1996, 2006, and 2017.

\section{Discussion}

In this study, we examined the landscape changes and their impacts on LST in Nuwara Eliya, Sri Lanka over a 21-year period (1996 to 2017). The results revealed that the urbanization pattern of Nuwara Eliya was concentrated around the city center areas in 1996 which then expanded towards the southern, southwestern, northwestern, and eastern parts by 2017. The development pattern of Nuwara Eliya is similar to that of other mountain cities (e.g., Kandy) in Sri Lanka [13]. The built-up land has expanded rapidly in the past 21 years (Tables 1 and 2, and Figure 4) with an overall increase of 1790.6 ha and an annual increase of 85.3 ha. The tourism industry has been reported to be the main driving force of the observed rapid development in the study area, as thousands of local and foreign tourists have been visiting Nuwara Eliya [49]. Previous studies, such as Baguio in the Philippines [14,46], Kandy in Sri Lanka [13,51], Bengaluru in India [64], Bogor in Indonesia [46], and Dalat in Vietnam [46], revealed that green spaces, such as forests, declined due to the urban development pressure in their respective study areas. However, our study revealed that the forest areas were intact throughout the study period, owing to strong government policies on forest preservation. Most of the forest areas located in Nuwara 
Eliya are protected. That has resulted in other LULC types other than forests being consumed. Our results demonstrate that BL expanded mainly at the expense of agricultural areas (Figure 5a).

The results revealed that the fraction of BL greatly influenced the LSTI in Nuwara Eliya. During the past 21 years, annual mean LST increased by $2.1{ }^{\circ} \mathrm{C}\left(18.9^{\circ} \mathrm{C}\right.$ in 1996 and $21.0^{\circ} \mathrm{C}$ in 2017). Additionally, the mean annual temperature difference between the urban $\left(\mathrm{URZ}_{1}\right)$ and $\operatorname{rural}(<10 \% \mathrm{BL})$ zones showed an increasing pattern, recording values of $1.0^{\circ} \mathrm{C}\left(19.8^{\circ} \mathrm{C}\right.$ in URZ 1 and $18.8^{\circ} \mathrm{C}$ in URZ 5$)$ in $1996,1.3^{\circ} \mathrm{C}$ in $2006\left(18.9{ }^{\circ} \mathrm{C}\right.$ in $\mathrm{URZ}_{1}$ and $17.6^{\circ} \mathrm{C}$ in $\left.\mathrm{URZ}_{6}\right)$, and $3.5^{\circ} \mathrm{C}$ in $2017\left(24.4^{\circ} \mathrm{C}\right.$ in $\mathrm{URZ}_{1}$ and $21.0^{\circ} \mathrm{C}$ in $\mathrm{URZ}_{18}$ ) (Figure 5a). These results show an interesting pattern of LST in the study area. Urbanization has considerably influenced the increasing annual mean LST of the study area. The highest mean LST values were recorded around the city center $\left(\mathrm{URZ}_{1}\right)$ in all the three-time points. The fractions of $\mathrm{BL}$ increased by $32.4 \%, 48.7 \%$, and $58.7 \%$, while the fraction of AL decreased by $43.6 \%, 29.6 \%$, and $15.8 \%$ in 1996, 2006, and 2017, respectively. The mean LST had a significant, positive relationship with the fraction of BL and significant negative relationship with the fraction of FL $(p<0.001)$ in all the three time-periods (Figure $5 b$ ). These results are similar to previous research findings in other mountain cities in Asia, such as Kandy in Sri Lanka [13], and Baguio in the Philippines [14]. The mean LST of all URZs (i.e., urban and rural combined) also showed an increasing pattern throughout the temporal extent of the study (1996-2017). The patterns observed in Nuwara Eliya not only showed changes in the landscape, but also agreed with other researchers that have reported an increasing trend of global temperatures at high-elevation regions [65-67]. It is thus plausible to speculate that these global temperatures in high-elevation regions could have also contributed to the observed LST increases in the study area and other urban environments worldwide.

The statistical relationship between mean LST and fraction of AL was different in all the three time-points. The mean LST showed a strongly significant, positive relationship with the fraction of AL in 1996, while in 2006, the relationship was significant, but weakly positive. However, in 2017, the relationship became weakly negative. We observed that poorly managed agricultural lands were converted into built-up lands during the 21 years of this study. The average fraction of AL exhibited a decreasing pattern, with values of $38.7 \%, 35.8 \%$, and $27.2 \%$ in 1996,2006 , and 2017 , respectively. This result is similar to the observations in other mountain cities in Sri Lanka [13]. The observed pattern is critical evidence for policymakers to introduce proper mechanisms for minimizing the adverse impacts associated with the rapid changes in the urban landscape of the study area. The negative impacts of urban development on agricultural land could cause several environmental issues [59], such as increased soil erosion [68], and landslides [69-71]. The rapid development of built-up land, resulting in increased levels of LST, could also negatively affect the tourism industry. Policies should be implemented to maintain the natural beauty of Nuwara Eliya for the sustainable tourism industry. Most tourists wish to enjoy the landscape and comfortable climate of the area [49,59].

The change in the urban-rural pattern provides a clear picture of the urbanization pattern in the study area. The urban-rural zones were demarcated using the fraction of $\mathrm{BL}(<10 \%)$. The rural zone exhibited a shifting pattern from 1996 to 2017 . The rural zone located in URZ $(1 \mathrm{~km}$ from the city center) in 1996 and the rural zone located in $\mathrm{URZ}_{6}(1.2 \mathrm{~km}$ from the city center) in 2006, had shifted to $\mathrm{URZ}_{18}$ by 2017 ( $3.8 \mathrm{~km}$ from the city center) (Figure 6a). Rapid changes to built-up land resulted in a shift in the rural zone away from the city center. Previous researchers have shown a similar trend in the shifting rural zone in mountain cities $[13,14]$. Results showed that the temperature of $\mathrm{URZ}_{1}$ was higher than that of the rural zones. The change in mean LST had a strong, positive relationship with the $\Delta$ fraction of BL and a strong negative relationship with the $\Delta$ fraction FL. However, the relationship between the $\Delta$ mean LST and $\Delta$ fraction of AL shifted from positive (1996 and 2006) to negative (2017). Policymakers should pay much attention to the shifting of the urban zone.

The mixture of land-use types, which is important for controlling LST [72], was investigated based on two indices: the AL/FL and BL/FL fraction ratios. The results showed that the AL/FL fraction ratio decreased from 1996 to 2017 (Figure 7a). The maximum AL/FL fraction ratio declined with values of 3.3, 2.3, and 1.3 in 1996, 2006, and 2017, respectively. The mean LST exhibited a significantly strong positive 
relationship with the AL/FL fraction ratio in 1996 and 2006. However, the degree of the relationship became weaker in 2017 due to the changes in the AL of the study area. The change in mean LST exhibited a positive relationship with the $\Delta(\mathrm{AL} / \mathrm{FL})$ fraction ratio over the three time-points (Figure 7c). On the other hand, the result of the BL/FL fraction ratio provided an indicator of the LSTI pattern in the study area. Changes in built-up land have been proven to be vital in understanding the LST changing pattern in urban areas $[20,33,73]$. The maximum BL/FL fraction ratio increased with values of $1.7,2.3$, and $3.4\left(\mathrm{URZ}_{1}\right)$ in 1996, 2006, and 2017, respectively. This result could be the reason for the observed increase in the mean LST over the 21-year study period (Figure 8a). The increasing BL/FL fraction ratio directly affected the LSTI in the study area, as the mean LST had a strongly significant relationship with the BL/FL fraction ratio over the 21-year study period.

The spatial distribution pattern of the BL, FL, and AL densities provided vital information for understanding the distribution pattern of the study area. The linear regression analysis results also revealed the vital formation of capturing the land use mixture of the study area. The average density of BL increased with values of $1.3 \%, 3.5 \%$, and $9.2 \%$ while the density of AL decreased with values $37.6 \%, 35.9 \%$, and $29.2 \%$ in 1996, 2006, and 2017, respectively (Figure 9a). This pattern indicates that the BL density has been increasing in the last 21 years. The linear regression analysis results showed that the coefficient of determination $\left(R^{2}\right)$ between mean LST and the density of BL increased from 0.04 to 0.29 from 1996 to 2017. This shows that the density of BL had a significant influence on the increase of LST in the study area. The $\mathrm{R}^{2}$ between the mean LST and the density of AL declined from 0.59 to 0. 47 from 1996 to 2017. This also shows that AL density had a positive influence on the increase of LST. The density of FL, on the other hand, influenced the control of LST in the study area, showing a negative, strongly significant relationship between the two (Figure 9b). Most of the previous studies have combined AL as green spaces, but AL of the Nuwara Eliya area has been positively influencing to the increase of LST in the three-time points. The policymakers and planners need to consider maintaining a good mixture of land use to control the LST pattern in the future.

On the whole, the rapid increase of built-up areas has been the main force driving the high temperatures recorded in 2017 compared to 2006 and 1996. The $\Delta$ mean LST exhibited a positive relationship with the $\Delta(\mathrm{BL} / \mathrm{FL})$ fraction ratio over the three time-points (Figure 8c). Previous research has demonstrated that having a mixture of land-use types can reduce temperatures in urban areas [72]. Based on the results from this study, maintenance of forest coverage will continue at a similar level due to governmental preservation policies. However, rapidly developing urban areas require proper urban planning to maintain sustainability. We have noticed that the present urban development pattern is unplanned. The walls and roofs of most of the buildings are also green in color; something which could reduce the indoor temperatures $[74,75]$. To achieve sustainable development, we recommend that urban planners and policymakers should consider constructing green belts along the main road, schools, hospitals, and other government buildings. The development pattern observed was mainly horizontal rather than vertical. Vertical development could reduce pressure on land and leave a lot of free land for improving greenspace coverage. Vertical development can also be used as a proxy indicator to understand urban-development intensity [76,77]. In addition, greenspace cover plays a vital role in reducing the impacts of LST in urban areas [78]. We believe that the current urban planning must focus on protecting this popular tourist destination in Sri Lanka's sustainably. The findings of this study can be used as an indicator for reorienting current urban planning policies to improve the natural and social environment in Nuwara Eliya.

Overall, this study successfully used annual mean LST to quantify landscape changes and their impacts on LSTI from 1996 to 2017. However, there are two main limitations of the study that should be considered. Firstly, comparing the mean LST change magnitudes with changes in observational air temperature measured from metrological stations could have helped in verifying our findings. However, that was challenging due to the unavailability of air temperature observational data from meteorological stations. Nonetheless, we used previous similar studies to validate our results, and we recommend that more studies should be conducted to confirm the increasing temperature in mountain 
cities of Sri Lanka. The lack of observational air temperature data in most developing countries has been the basis for the proliferation of UHI studies based on LST retrieved from remote sensing satellite imagery, compared to atmospheric UHI studies based on measured air temperature. Secondly, we believe that horizontal and vertical development of buildings both play a vital role in controlling the annual mean LST of the study area. However, vertical data on various types of buildings and built-structures were not used in this study due to unavailability in Sri Lanka. Thus, the results should be interpreted in the context of those limitations.

\section{Conclusions}

The spatial distribution of LST provides vital information for understanding the local climatic variation of cities and can be used as a proxy indicator to introduce sufficient measures to minimize the negative impacts associated with high LST. This study revealed that Nuwara Eliya had undergone rapid urban development over the 21 years studied. The study used multiple images to extract the median annual LSTs for 1996, 2006, and 2017. The results revealed that the annual mean LST increased by $2.1^{\circ} \mathrm{C}$ over the past 21 years. The annual mean LST difference between the urban and rural zones increased from $1.0^{\circ} \mathrm{C}$ to $3.5^{\circ} \mathrm{C}$ from 1996 to 2017 . The study shows that rapid development was spreading towards rural zones, and the fraction of BL influenced the increase in annual mean LST. The government policies have been protecting the FL, resulting in minimal changes which have been the major contributor to the control of the LST pattern. This study recommends that having a mixture of land-use types would considerably control the increasing LST in the study area. Thus, policymakers need to consider the importance of the land use mixture to reduce the impacts of a high LST in the study area. The future urban policy must focus on maintaining the natural splendor of the Nuwara Eliya to promote tourism in the study area and Sri Lanka. Nuwara Eliya is renowned as a tourist destination in Sri Lanka. Thus, the findings of this study can be used as an indicator to introduce sustainable future landscape and urban planning to protect the world-renowned tourist hub of Sri Lanka.

Author Contributions: The author to receive correspondence, M.R., proposed the topic and spearheaded the data processing and analysis, as well as the writing of the manuscript. Y.M., D.D., and M.S. helped in the design, research implementation, analysis, and the writing of the manuscript.

Funding: This study was supported by the Japan Society for the Promotion of Science (JSPS) through Grant-in-Aid for Scientific Research (B) 18H00763 (2018-20).

Acknowledgments: The authors are grateful to the anonymous reviewers for their helpful comments and suggestions to improve the quality of this paper.

Conflicts of Interest: The authors declare no conflict of interest.

\section{Appendix A}

Table A1. Properties of the Landsat images (Level 2) used in this study.

\begin{tabular}{|c|c|c|c|c|}
\hline Sensor & Scene ID & $\begin{array}{l}\text { Acquisition } \\
\text { Date }\end{array}$ & $\begin{array}{l}\text { Time } \\
\text { (GMT) }\end{array}$ & $\begin{array}{l}\text { Cloud Cover (\%) } \\
\text { in Landsat Title }\end{array}$ \\
\hline \multirow{13}{*}{ Landsat $5 \mathrm{TM}$} & LT05_L1TP_141055_19960221_20170106_01_T1 & 1996-02-21 & 03:59:45 & 19 \\
\hline & LT05_L1TP_141055_19960308_20170106_01_T1 & 1996-03-08 & 04:00:49 & 6 \\
\hline & LT05_L1TP_141055_19960324_20170105_01_T1 & 1996-03-24 & 04:01:51 & 11 \\
\hline & LT05_L1TP_141055_19960409_20170105_01_T1 & 1996-04-09 & 04:02:51 & 46 \\
\hline & LT05_L1TP_141055_19960425_20170104_01_T1 & $1996-04-25$ & 04:03:49 & 9 \\
\hline & LT05_L1TP_141055_19960511_20170104_01_T1 & $1996-05-11$ & 04:04:46 & 9 \\
\hline & LT05_L1TP_141055_19960527_20170104_01_T1 & $1996-05-27$ & 04:05:41 & 29 \\
\hline & LT05_L1TP_141055_19960730_20170103_01_T1 & 1996-07-30 & 04:09:06 & 78 \\
\hline & LT05_L1TP_141055_19960815_20170103_01_T1 & 1996-08-15 & 04:09:56 & 66 \\
\hline & LT05_L1TP_141055_19960831_20170103_01_T1 & 1996-08-31 & 04:10:48 & 41 \\
\hline & LT05_L1TP_141055_19960916_20170102_01_T1 & $1996-09-16$ & 04:11:41 & 70 \\
\hline & LT05_L1TP_141055_19961002_20170102_01_T1 & 1996-10-02 & 04:12:33 & 48 \\
\hline & LT05_L1TP_141055_19961103_20170102_01_T1 & 1996-11-03 & 04:14:09 & 38 \\
\hline
\end{tabular}


Table A1. Cont.

\begin{tabular}{|c|c|c|c|c|}
\hline Sensor & Scene ID & $\begin{array}{l}\text { Acquisition } \\
\text { Date }\end{array}$ & $\begin{array}{l}\text { Time } \\
\text { (GMT) }\end{array}$ & $\begin{array}{l}\text { Cloud Cover (\%) } \\
\text { in Landsat Title }\end{array}$ \\
\hline \multirow{17}{*}{ Landsat 5 TM } & LT05_L1TP_141055_19961119_20170101_01_T1 & 1996-11-19 & 04:14:53 & 19 \\
\hline & LT05_L1TP_141055_19961205_20170101_01_T1 & 1996-12-05 & 04:15:40 & 84 \\
\hline & LT05_L1TP_141055_20060131_20161123_01_T1 & 2006-01-31 & 04:44:06 & 46 \\
\hline & LT05_L1TP_141055_20060216_20161123_01_T1 & 2006-02-16 & 04:44:28 & 28 \\
\hline & LT05_L1TP_141055_20060304_20161122_01_T1 & 2006-03-04 & 04:44:49 & 41 \\
\hline & LT05_L1TP_141055_20060405_20161123_01_T1 & 2006-04-05 & 04:45:26 & 10 \\
\hline & LT05_L1TP_141055_20060421_20161122_01_T1 & 2006-04-21 & 04:45:41 & 68 \\
\hline & LT05_L1TP_141055_20060507_20161122_01_T1 & 2006-05-07 & 04:45:55 & 33 \\
\hline & LT05_L1TP_141055_20060523_20161121_01_T1 & 2006-05-23 & 04:46:07 & 31 \\
\hline & LT05_L1TP_141055_20060608_20161121_01_T1 & 2006-06-08 & 04:46:23 & 27 \\
\hline & LT05_L1TP_141055_20060624_20161121_01_T1 & 2006-06-24 & 04:46:39 & 72 \\
\hline & LT05_L1TP_141055_20060710_20161120_01_T1 & 2006-07-10 & 04:46:53 & 30 \\
\hline & LT05_L1TP_141055_20060811_20161119_01_T1 & 2006-08-11 & 04:47:17 & 79 \\
\hline & LT05_L1TP_141055_20060827_20161119_01_T1 & 2006-08-27 & 04:47:29 & 45 \\
\hline & LT05_L1TP_141055_20060912_20161119_01_T1 & 2006-09-12 & 04:47:41 & 57 \\
\hline & LT05_L1TP_141055_20060928_20161119_01_T1 & 2006-09-28 & 04:47:52 & 55 \\
\hline & LT05_L1TP_141055_20061014_20161118_01_T1 & 2006-10-14 & 04:48:03 & 22 \\
\hline \multirow{22}{*}{$\begin{array}{l}\text { Landsat } 8 \\
\text { OLI/TIRS }\end{array}$} & LT05_L1TP_141055_20061030_20161118_01_T1 & $2006-10-30$ & 04:48:13 & 30 \\
\hline & LT05_L1TP_141055_20061115_20161118_01_T1 & 2006-11-15 & 04:48:21 & 60 \\
\hline & LC08_L1TP_141055_20170113_20170311_01_T1 & 2017-01-13 & 04:54:05 & 3 \\
\hline & LC08_L1TP_141055_20170129_20170214_01_T1 & 2017-01-29 & 04:53:59 & 40 \\
\hline & LC08_L1TP_141055_20170214_20170228_01_T1 & 2017-02-14 & 04:53:52 & 68 \\
\hline & LC08_L1TP_141055_20170302_20170316_01_T1 & 2017-03-02 & 04:53:46 & 64 \\
\hline & LC08_L1TP_141055_20170318_20170328_01_T1 & 2017-03-18 & 04:53:36 & 13 \\
\hline & LC08_L1TP_141055_20170403_20170414_01_T1 & 2017-04-03 & 04:53:29 & 16 \\
\hline & LC08_L1TP_141055_20170419_20170501_01_T1 & 2017-04-19 & 04:53:20 & 15 \\
\hline & LC08_L1TP_141055_20170505_20170515_01_T1 & 2017-05-05 & 04:53:13 & 32 \\
\hline & LC08_L1TP_141055_20170606_20170616_01_T1 & 2017-06-06 & 04:53:34 & 54 \\
\hline & LC08_L1TP_141055_20170622_20170630_01_T1 & 2017-06-22 & 04:53:40 & 28 \\
\hline & LC08_L1TP_141055_20170708_20170716_01_T1 & 2017-07-08 & 04:53:43 & 44 \\
\hline & LC08_L1TP_141055_20170724_20170809_01_T1 & $2017-07-24$ & 04:53:49 & 38 \\
\hline & LC08_L1TP_141055_20170809_20170824_01_T1 & 2017-08-09 & 04:53:56 & 47 \\
\hline & LC08_L1TP_141055_20170825_20170913_01_T1 & $2017-08-25$ & 04:54:00 & 38 \\
\hline & LC08_L1TP_141055_20170910_20170927_01_T1 & 2017-09-10 & 04:54:02 & 61 \\
\hline & LC08_L1TP_141055_20170926_20171013_01_T1 & $2017-09-26$ & 04:54:07 & 82 \\
\hline & LC08_L1TP_141055_20171012_20171024_01_T1 & 2017-10-12 & 04:54:12 & 76 \\
\hline & LC08_L1TP_141055_20171028_20171108_01_T1 & $2017-10-28$ & 04:54:13 & 19 \\
\hline & LC08_L1TP_141055_20171113_20171121_01_T1 & $2017-11-13$ & 04:54:10 & 38 \\
\hline & LC08_L1TP_141055_20171215_20171223_01_T1 & 2017-12-15 & 04:54:05 & 32 \\
\hline
\end{tabular}

Code A1. The code used to generate median temperature of Landsat 5 TM images for 1996 and 2006.

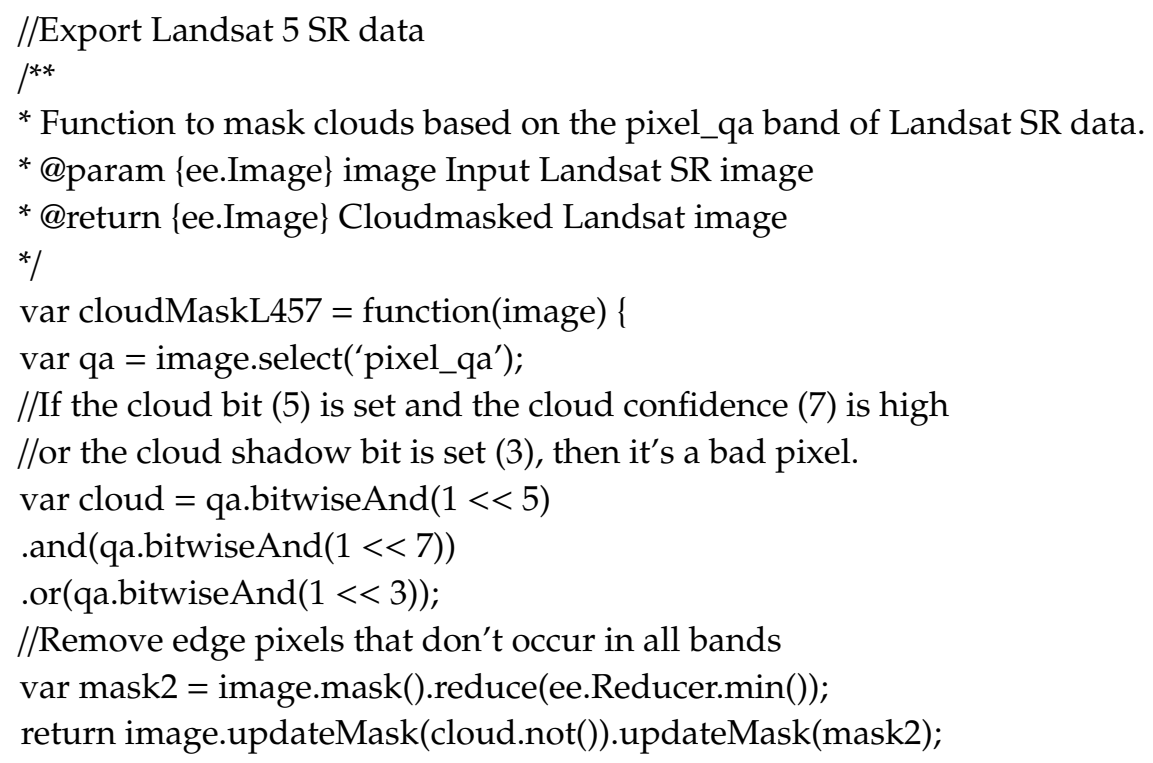




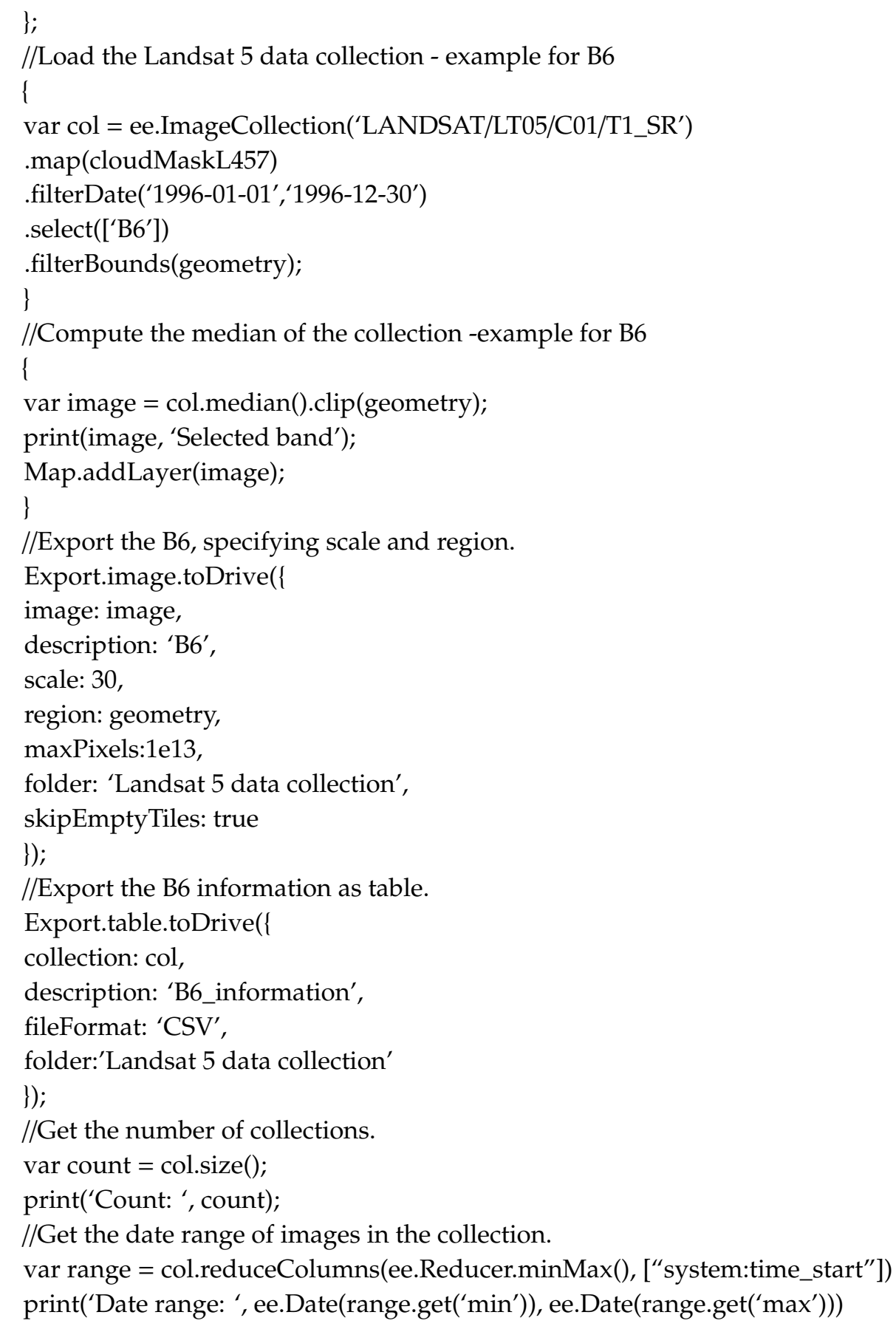

Code A2. The code used to generate median temperature of Landsat 8 images for 2017. //Export Landsat 8 SR data

/**

* Function to mask clouds based on the pixel_qa band of Landsat 8 SR data.

* @param \{ee.Image\} image input Landsat 8 SR image

*@return \{ee.Image\} cloudmasked Landsat 8 image

*/

function maskL8sr(image) \{

//Bits 3 and 5 are cloud shadow and cloud, respectively.

var cloudShadowBitMask $=(1<<3)$;

var cloudsBitMask $=(1<<5)$; 
//Get the pixel QA band.

var qa = image.select('pixel_qa');

//Both flags should be set to zero, indicating clear conditions.

var mask = qa.bitwiseAnd(cloudShadowBitMask).eq(0)

.and(qa.bitwiseAnd(cloudsBitMask).eq(0));

return image.updateMask(mask);

\}

//Load the Landsat 8 data collection - example for B10

\{

var col = ee.ImageCollection('LANDSAT/LC08/C01/T1_SR')

.map(maskL8sr)

.filterDate('2018-01-01','2018-12-30')

.select(['B10'])

.filterBounds(geometry);

\}

//Compute the median of the collection - example for B10

\{

var image $=$ col.median().clip(geometry);

print(image, 'Selected band');

Map.addLayer(image);

\}

//Export the B10, specifying scale and region.

Export.image.toDrive(\{

image: image,

description: 'B10',

scale: 30 ,

region: geometry,

maxPixels:1e13,

folder: 'Landsat 8 data collection',

skipEmptyTiles: true

\});

//Export the B10 information as table.

Export.table.toDrive $(\{$

collection: col,

description: 'B10_information',

fileFormat: 'CSV',

folder:'Landsat 8 data collection'

\});

//Get the number of collections.

var count $=$ col.size ();

print('Count: ', count);

//Get the date range of images in the collection.

var range $=$ col.reduceColumns(ee.Reducer.minMax(), ["system:time_start"])

print('Date range: ', ee.Date(range.get('min')), ee.Date(range.get('max'))) 
Table A2. Error matrix for the classified 1996 land use/cover map, classified.

\begin{tabular}{|c|c|c|c|c|c|c|c|}
\hline \multirow{2}{*}{ Classified Data } & \multicolumn{5}{|c|}{ Reference Data } & \multirow[b]{2}{*}{ Total } & \multirow[b]{2}{*}{ User's Accuracy (\%) } \\
\hline & Built-up & Forest & Agricultural Land & Other & Water & & \\
\hline Built-up & 72 & 8 & 6 & 3 & 0 & 89 & 80.9 \\
\hline Agricultural Land & 5 & 17 & 140 & 2 & 2 & 166 & 84.3 \\
\hline Other Land & 2 & 2 & 3 & 34 & 1 & 42 & 81.0 \\
\hline Water & 0 & 2 & 2 & 0 & 16 & 20 & 80.0 \\
\hline
\end{tabular}

Table A3. Error matrix for the classified 2006 land use/cover map, classified.

\begin{tabular}{|c|c|c|c|c|c|c|c|}
\hline Classified Data & \multicolumn{5}{|c|}{ Reference Data } & Total & User's Accuracy (\%) \\
\hline Built-up & 98 & 2 & 5 & 0 & 0 & 105 & 93.3 \\
\hline Agricultural Land & 4 & 5 & 155 & 1 & 1 & 166 & 93.4 \\
\hline Other Land & 0 & 0 & 1 & 5 & 1 & 7 & 71.4 \\
\hline Water & 0 & 1 & 1 & 1 & 26 & 29 & 89.7 \\
\hline
\end{tabular}

Table A4. Error matrix for the classified 1996 land use/cover map, classified.

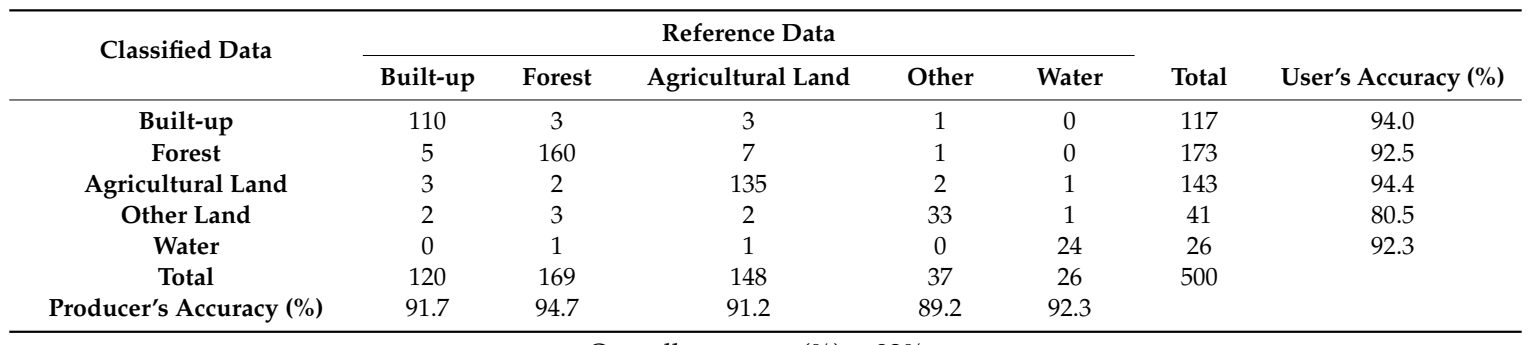

Overall accuracy $(\%)=92 \%$.

\section{References}

1. Chen, X.; Zhang, Y. Impacts of urban surface characteristics on spatiotemporal pattern of land surface temperature in Kunming of China. Sustain. Cities Soc. 2017, 32, 87-99. [CrossRef]

2. Thi Van, T.; Bao, H.D.X. Study of the impact of urban development on surface temperature using remote sensing in Ho Chi Minh City, Northern Vietnam. Geogr. Res. 2010, 48, 86-96. [CrossRef]

3. Ranagalage, M.; Estoque, R.C.; Murayama, Y. An urban heat island study of the Colombo Metropolitan Area, Sri Lanka, based on Landsat data (1997-2017). ISPRS Int. J. Geo-Inf. 2017, 6, 189. [CrossRef]

4. Ranagalage, M.; Estoque, R.C.; Zhang, X.; Murayama, Y. Spatial changes of urban heat island formation in the Colombo District, Sri Lanka: Implications for sustainability planning. Sustainability 2018, 10, 1367. [CrossRef]

5. Son, N.-T.; Chen, C.-F.; Chen, C.-R.; Thanh, B.-X.; Vuong, T.-H. Assessment of urbanization and urban heat islands in Ho Chi Minh City, Vietnam using Landsat data. Sustain. Cities Soc. 2017, 30, 150-161. [CrossRef]

6. Hou, H.; Wang, R.; Murayama, Y. Scenario-based modelling for urban sustainability focusing on changes in cropland under rapid urbanization: A case study of Hangzhou from 1990 to 2035. Sci. Total Environ. 2019, 661, 422-431. [CrossRef] [PubMed]

7. Alphan, H. Land-use change and urbanization of Adana, Turkey. Land Degrad. Dev. 2003, 14, 575-586. [CrossRef]

8. Shalaby, A.; Ghar, M.A.; Tateishi, R. Desertification impact assessment in Egypt using low resolution satellite data and GIS. Int. J. Environ. Stud. 2004, 61, 375-383. [CrossRef] 
9. Simwanda, M.; Murayama, Y. Spatiotemporal patterns of urban land use change in the rapidly growing city of Lusaka, Zambia: Implications for sustainable urban development. Sustain. Cities Soc. 2018, 39, 262-274. [CrossRef]

10. El Araby, M. Urban growth and environmental degradation. Cities 2002, 19, 389-400. [CrossRef]

11. Debela, T.H.; Beyene, A.; Tesfahun, E.; Getaneh, A.; Gize, A.; Mekonnen, Z. Fecal contamination of soil and water in sub-Saharan Africa cities: The case of Addis Ababa, Ethiopia. Ecohydrol. Hydrobiol. 2018, 18, 225-230. [CrossRef]

12. Knudsen, A.B.; Slooff, R. Vector-borne disease problems in rapid urbanization: New approaches to vector control. Bull. World Health Organ. 1992, 70, 1-6. [PubMed]

13. Ranagalage, M.; Dissanayake, D.; Murayama, Y.; Zhang, X.; Estoque, R.C.; Perera, E.; Morimoto, T. Quantifying surface urban heat island formation in the World Heritage Tropical Mountain City of Sri Lanka. ISPRS Int. J. Geo-Inf. 2018, 7, 341. [CrossRef]

14. Estoque, R.C.; Murayama, Y. Monitoring surface urban heat island formation in a tropical mountain city using Landsat data (1987-2015). ISPRS J. Photogramm. Remote Sens. 2017, 133, 18-29. [CrossRef]

15. Voogt, J.A.; Oke, T.R. Thermal remote sensing of urban climates. Remote Sens. Environ. 2003, 86, 370-384. [CrossRef]

16. Estoque, R.C.; Murayama, Y.; Myint, S.W. Effects of landscape composition and pattern on land surface temperature: An urban heat island study in the megacities of Southeast Asia. Sci. Total Environ. 2017, 577, 349-359. [CrossRef] [PubMed]

17. Weng, Q. A remote sensing-GIS evaluation of urban expansion and its impact on surface temperature in the Zhujiang Delta, China. Int. J. Remote Sens. 2014, 22, 1999-2014.

18. Singh, P.; Kikon, N.; Verma, P. Impact of land use change and urbanization on urban heat island in Lucknow city, Central India. A remote sensing based estimate. Sustain. Cities Soc. 2017, 32, 100-114. [CrossRef]

19. Mirzaei, P.A. Recent challenges in modeling of urban heat island. Sustain. Cities Soc. 2015, 19, $200-206$. [CrossRef]

20. Rousta, I.; Sarif, M.O.; Gupta, R.D.; Olafsson, H.; Ranagalage, M.; Murayama, Y.; Zhang, H.; Mushore, T.D. Spatiotemporal analysis of land use/land cover and its effects on surface urban heat island using Landsat data: A case study of Metropolitan City Tehran (1988-2018). Sustainability 2018, 10, 4433. [CrossRef]

21. Teferi, E.; Abraha, H. Urban heat island effect of Addis Ababa City: Implications of urban green spaces for climate change adaptation. In Climate Change Adaptation in Africa; Springer: Berlin, Germany, 2017.

22. Tran, H.; Uchihama, D.; Ochi, S.; Yasuoka, Y. Assessment with satellite data of the urban heat island effects in Asian mega cities. Int. J. Appl. Earth Obs. Geoinf. 2006, 8, 34-48. [CrossRef]

23. Van Nguyen, O.; Kawamura, K.; Trong, D.P.; Gong, Z.; Suwandana, E. Temporal change and its spatial variety on land surface temperature and land use changes in the Red River Delta, Vietnam, using MODIS time-series imagery. Environ. Monit. Assess. 2015, 187, 464. [CrossRef] [PubMed]

24. Ayanlade, A. Seasonality in the daytime and night-time intensity of land surface temperature in a tropical city area. Sci. Total Environ. 2016, 557-558, 415-424. [CrossRef] [PubMed]

25. Zhou, D.; Zhang, L.; Hao, L.; Sun, G.; Liu, Y.; Zhu, C. Spatiotemporal trends of urban heat island effect along the urban development intensity gradient in China. Sci. Total Environ. 2016, 544, 617-626. [CrossRef] [PubMed]

26. Marconcini, M.; Metz, A.; Esch, T.; Zeidler, J. Global urban growth monitoring by means of SAR data. In Proceedings of the 2014 IEEE Geoscience and Remote Sensing Symposium, Quebec, QC, Canada, 13-18 July 2014; pp. 1477-1480.

27. Paranunzio, R.; Ceola, S.; Laio, F.; Montanari, A. Evaluating the effects of urbanization evolution on air temperature trends using nightlight satellite data. Atmosphere 2019, 10, 117. [CrossRef]

28. Zhou, Y.; Smith, S.J.; Zhao, K.; Imhoff, M.; Thomson, A.; Bond-Lamberty, B.; Asrar, G.R.; Zhang, X.; He, C.; Elvidge, C.D. A global map of urban extent from nightlights. Environ. Res. Lett. 2015, 10, 2000-2010. [CrossRef]

29. Weng, Q. Thermal infrared remote sensing for urban climate and environmental studies: Methods, applications, and trends. ISPRS J. Photogramm. Remote Sens. 2009, 64, 335-344. [CrossRef]

30. Weng, Q.; Lu, D.; Schubring, J. Estimation of land surface temperature-vegetation abundance relationship for urban heat island studies. Remote Sens. Environ. 2004, 89, 467-483. [CrossRef] 
31. Bhaduri, B.; Bright, E.; Coleman, P.; Urban, M.L. LandScan USA: A high-resolution geospatial and temporal modeling approach for population distribution and dynamics. GeoJournal 2007, 69, 103-117. [CrossRef]

32. Zhang, X.; Estoque, R.C.; Murayama, Y. An urban heat island study in Nanchang City, China based on land surface temperature and social-ecological variables. Sustain. Cities Soc. 2017, 32, 557-568. [CrossRef]

33. Dissanayake, D.; Morimoto, T.; Ranagalage, M.; Murayama, Y. Impact of urban surface characteristics and socio-economic variables on the spatial variation of land surface temperature in Lagos City, Nigeria. Sustainability 2019, 11, 25. [CrossRef]

34. Bhargava, A.; Lakmini, S.; Bhargava, S. Urban Heat Island Effect: It's Relevance in Urban Planning. J. Biodivers. Endanger. Species 2017, 5, 5-187.

35. $\mathrm{Xu}, \mathrm{S}$. An approach to analyzing the intensity of the daytime surface urban heat island effect at a local scale. Environ. Monit. Assess. 2009, 151, 289-300. [CrossRef] [PubMed]

36. Li, Y.Y.; Zhang, H.; Kainz, W. Monitoring patterns of urban heat islands of the fast-growing Shanghai metropolis, China: Using time-series of Landsat TM/ETM+ data. Int. J. Appl. Earth Obs. Geoinf. 2012, 19, 127-138. [CrossRef]

37. Senanayake, I.P.; Welivitiya, W.D.D.P.; Nadeeka, P.M. Remote sensing based analysis of urban heat islands with vegetation cover in Colombo city, Sri Lanka using Landsat-7 ETM+ data. Urban Clim. 2013, 5, $19-35$. [CrossRef]

38. Sakakibara, Y.; Owa, K. Urban-rural temperature differences in coastal cities: Influence of rural sites. Int. J. Climatol. 2005, 25, 811-820. [CrossRef]

39. Myint, S.W.; Brazel, A.; Okin, G.; Buyantuyev, A. Combined effects of impervious surface and vegetation cover on air temperature variations in a rapidly expanding desert city. GIScience Remote Sens. 2010, 47, 301-320. [CrossRef]

40. Ravanelli, R.; Nascetti, A.; Cirigliano, R.V.; Di Rico, C.; Leuzzi, G.; Monti, P.; Crespi, M. Monitoring the impact of land cover change on surface urban heat island through Google Earth Engine: Proposal of a global methodology, first applications and problems. Remote Sens. 2018, 10, 1488. [CrossRef]

41. Parastatidis, D.; Mitraka, Z.; Chrysoulakis, N.; Abrams, M. Online global land surface temperature estimation from landsat. Remote Sens. 2017, 9, 1208. [CrossRef]

42. Stewart, I.; Oke, T. Classifying urban climate field sites by "local climate zones": The case of nagano, japan. In Proceedings of the Seventh International Conference on Urban Climate, Yokohama, Japan, 29-30 June 2009.

43. Oke, T.R. Initial Guidance to Obtain Representative Meteorological Observations at Urban Sites; World Meteorological Organization: Geneva, Switzerland, 2004.

44. Ranagalage, M.; Estoque, R.C.; Handayani, H.H.; Zhang, X.; Morimoto, T.; Tadono, T.; Murayama, Y. Relation between urban volume and land surface temperature: A comparative study of planned and traditional cities in Japan. Sustainability 2018, 10, 2366. [CrossRef]

45. Priyankara, P.; Ranagalage, M.; Dissanayake, D.; Morimoto, T.; Murayama, Y. Spatial process of surface urban heat island in rapidly growing Seoul metropolitan area for sustainable urban planning using Landsat Data. Climate 2019, 7, 110. [CrossRef]

46. Estoque, R.C.; Murayama, Y. Quantifying landscape pattern and ecosystem service value changes in four rapidly urbanizing hill stations of Southeast Asia. Landsc. Ecol. 2016, 31, 1481-1507. [CrossRef]

47. Estoque, R.C.; Murayama, Y. City Profile: Baguio. Cities 2013, 30, 240-251. [CrossRef]

48. Crossette, B. The Great Hill Stations of Asia; Basic Books: New York, NY, USA, 1999; Volume 73.

49. Jayasinghe, M.K.D.; Gnanapala, W.K.A.; Sandaruwani, J.A.R. Factors affecting tourists' perception and satisfaction in Nuwara Eliya, Sri Lanka. Ilorin J. Econ. Policy 2015, 2, 1-15.

50. Weerasinghe, W.W.K. Transformation of the landscape of Nuwara-Eliya. Ph.D. Thesis, University of Moratuwa, Colombo, Sri Lanka, 2003.

51. Dissanayake, D.; Morimoto, T.; Ranagalage, M.; Murayama, Y. Land-use/land-cover changes and their impact on surface urban heat islands: Case study of Kandy City, Sri Lanka. Climate 2019, 7, 99. [CrossRef]

52. Google Erath Engine, Landsat Collection Structure. Available online: https://developers.google.com/earthengine/landsat (accessed on 25 May 2019).

53. Google Erath Engine, Image Collection Reductions. Available online: https://developers.google.com/earthengine/reducers_image_collection (accessed on 25 May 2019). 
54. Sobrino, J.A.; Jiménez-Muñoz, J.C.; Paolini, L. Land surface temperature retrieval from LANDSAT TM 5. Remote Sens. Environ. 2004, 90, 434-440. [CrossRef]

55. Zhang, Y.; Odeh, I.O.A.; Han, C. Bi-temporal characterization of land surface temperature in relation to impervious surface area, NDVI and NDBI, using a sub-pixel image analysis. Int. J. Appl. Earth Obs. Geoinf. 2009, 11, 256-264. [CrossRef]

56. Huang, C.; Davis, L.S.; Townshend, J.R.G. An assessment of support vector machines for land cover classification. Int. J. Remote Sens. 2002, 23, 725-749. [CrossRef]

57. Yang, X. Parameterizing Support Vector Machines for land cover classification. Photogramm. Eng. Remote Sens. 2011, 77, 27-37. [CrossRef]

58. Shi, D.; Yang, X. Support vector machines for land cover mapping from remote sensor imagery. In Monitoring and Modeling of Global Changes: A Geomatics Perspective; Springer: Dordrecht, The Netherlands, 2015; pp. 265-279.

59. Ranagalage, M.; Wang, R.; Gunarathna, M.H.J.P.; Dissanayake, D.; Murayama, Y.; Simwanda, M. Spatial forecasting of the landscape in rapidly urbanizing hill stations of South Asia: A case study of Nuwara Eliya, Sri Lanka (1996-2037). Remote Sens. 2019, 11, 1743. [CrossRef]

60. Gunaalan, K.; Ranagalage, M.; Gunarathna, M.H.J.P.; Kumari, M.K.N.; Vithanage, M.; Srivaratharasan, T.; Saravanan, S.; Warnasuriya, T.W.S. Application of geospatial techniques for groundwater quality and availability assessment: A case study in Jaffna Peninsula, Sri Lanka. ISPRS Int. J. Geo-Inf. 2018, 7, 20. [CrossRef]

61. Simwanda, M.; Ranagalage, M.; Estoque, R.C.; Murayama, Y. Spatial analysis of surface urban heat islands in four rapidly growing African Cities. Remote Sens. 2019, 11, 1645. [CrossRef]

62. Dissanayake, D.; Morimoto, T.; Murayama, Y.; Ranagalage, M. Impact of landscape structure on the variation of land surface temperature in Sub-Saharan Region: A case study of Addis Ababa using Landsat data (1986-2016). Sustainability 2019, 11, 2257. [CrossRef]

63. Department of Forest. Forest Ordinance; Department of Forest: Sri Jayawardenepura Kotte, Sri Lanka, 1908.

64. Sultana, S.; Satyanarayana, A.N.V. Urban heat island intensity during winter over metropolitan cities of India using remote-sensing techniques: Impact of urbanization. Int. J. Remote Sens. 2018, 39, 6692-6730. [CrossRef]

65. Pepin, N.; Bradley, R.S.; Diaz, H.F.; Baraer, M.; Caceres, E.B.; Forsythe, N.; Fowler, H.; Greenwood, G.; Hashmi, M.Z.; Liu, X.D.; et al. Elevation-dependent warming in mountain regions of the world. Nat. Clim. Chang. 2015, 5, 424-430.

66. Diaz, H.F.; Bradley, R.S.; Ning, L. Climatic changes in mountain regions of the American Cordillera and the tropics: Historical changes and future outlook. Arct. Antarct Alp. Res. 2014, 46, 735-743. [CrossRef]

67. Bradley, R.S.; Keimig, F.T.; Diaz, H.F.; Hardy, D.R. Recent changes in freezing level heights in the Tropics with implications for the deglacierization of high mountain regions. Geophys. Res. Lett. 2009, 36, 2-5. [CrossRef]

68. Dissanayake, D.; Morimoto, T.; Ranagalage, M. Accessing the soil erosion rate based on RUSLE model for sustainable land use management: A case study of the Kotmale watershed, Sri Lanka. Model. Earth Syst. Environ. 2018, 4, 291-306. [CrossRef]

69. Ranagalage, M. Landslide hazards assessment in Nuwara Eliya District in Sri Lanka. In Proceedings of the Japanese Geographical Meeting, Tsukuba, Japan, 28-30 March 2017; p. 100336.

70. Perera, E.N.C.; Jayawardana, D.T.; Jayasinghe, P.; Ranagalage, M. Landslide vulnerability assessment based on entropy method: A case study from Kegalle district, Sri Lanka. Model. Earth Syst. Environ. 2019, 1-15. [CrossRef]

71. Perera, E.N.C.; Jayawardana, D.T.; Ranagalage, M.; Jayasinghe, P. Spatial multi criteria evaluation (SMCE) model for landslide hazard zonation in tropical hilly environment: A case study from Kegalle. Geoinform. Geostat. Overv. 2018, S3. [CrossRef]

72. Thanh Hoan, N.; Liou, Y.-A.; Nguyen, K.-A.; Sharma, R.; Tran, D.-P.; Liou, C.-L.; Cham, D. Assessing the effects of land-use types in surface urban heat islands for developing comfortable living in Hanoi City. Remote Sens. 2018, 10, 1965. [CrossRef]

73. Yuan, F.; Bauer, M.E. Comparison of impervious surface area and normalized difference vegetation index as indicators of surface urban heat island effects in Landsat imagery. Remote Sens. Environ. 2007, 106, 375-386. [CrossRef] 
74. Galagoda, R.U.; Jayasinghe, G.Y.; Halwatura, R.U.; Rupasinghe, H.T. The impact of urban green infrastructure as a sustainable approach towards tropical micro-climatic changes and human thermal comfort. Urban For. Urban Green. 2018, 34, 1-9. [CrossRef]

75. Manawadu, L.; Ranagalage, M. Urban heat islands and vegetation cover as a controlling factor. In Proceedings of the International Forestry and Environment Symposium 2013 of the Department of Forestry and Environmental Science, University of Sri Jayewardenepura, Thulhiriya, Sri Lanka, 10-11 January 2014; p. 125.

76. Estoque, R.C.; Murayama, Y.; Ranagalage, M.; Hou, H.; Subasinghe, S. Validating ALOS PRISM DSM-derived surface feature height: Implications for urban volume estimation. Tsukuba Geoenviron. Sci. 2017, 13, 13-22.

77. Ranagalage, M.; Murayama, Y. Measurement of urban built-up volume using remote sensing data and geospatial techniques. Tsukuba Geoenviron. Sci. 2018, 14, 19-29.

78. Handayani, H.H.; Murayama, Y.; Ranagalage, M.; Liu, F.; Dissanayake, D. Geospatial analysis of horizontal and vertical urban expansion using multi-spatial resolution data: A case study of Surabaya, Indonesia. Remote Sens. 2018, 10, 1599. [CrossRef]

(C) 2019 by the authors. Licensee MDPI, Basel, Switzerland. This article is an open access article distributed under the terms and conditions of the Creative Commons Attribution (CC BY) license (http://creativecommons.org/licenses/by/4.0/). 